\title{
Species better track climate warming in the oceans than on land
}

\author{
Lenoir Jonathan ${ }^{1,{ }^{*}}$, Bertrand Romain ${ }^{2,3}$, Comte Lise ${ }^{4,5}$, Bourgeaud Luana ${ }^{3}$, Hattab Tarek ${ }^{6}$, \\ Murienne Jérôme ${ }^{3}$, Grenouillet Gaël 3,7
}

\author{
${ }^{1}$ Ecologie et Dynamique des Systèmes Anthropisés (EDYSAN), UMR7058, CNRS and Université de \\ Picardie Jules Verne, Amiens, France \\ ${ }^{2}$ Centre for Biodiversity Theory and Modelling, Theoretical and Experimental Ecology Station, \\ UMR5321, CNRS and Université Toulouse III - Paul Sabatier, Moulis, France \\ ${ }^{3}$ Laboratoire Evolution et Diversité Biologique, UMR5174, Université Toulouse III - Paul Sabatier, \\ CNRS, IRD and UPS, Toulouse, France \\ ${ }^{4}$ School of Aquatic and Fishery Sciences, University of Washington, Seattle, WA, USA \\ ${ }^{5}$ Department of Ecology and Evolutionary Biology, The University of Tennessee, Knoxville, TN, USA \\ ${ }^{6}$ MARBEC, Univ Montpellier, CNRS, IFREMER and IRD, Sète, France \\ 7 Institut Universitaire de France, Paris, France \\ * Corresponding author : Jonathan Lenoir, email address : jonathan.lenoir@u-picardie.fr
}

\begin{abstract}
:
There is mounting evidence of species redistribution as climate warms. Yet, our knowledge of the coupling between species range shifts and isotherm shifts remains limited. Here, we introduce BioShifts-a global geo-database of 30,534 range shifts. Despite a spatial imbalance towards the most developed regions of the Northern Hemisphere and a taxonomic bias towards the most charismatic animals and plants of the planet, data show that marine species are better at tracking isotherm shifts, and move towards the pole six times faster than terrestrial species. More specifically, we find that marine species closely track shifting isotherms in warm and relatively undisturbed waters (for example, the Central Pacific Basin) or in cold waters subject to high human pressures (for example, the North Sea). On land, human activities impede the capacity of terrestrial species to track isotherm shifts in latitude, with some species shifting in the opposite direction to isotherms. Along elevational gradients, species follow the direction of isotherm shifts but at a pace that is much slower than expected, especially in areas with warm climates. Our results suggest that terrestrial species are lagging behind shifting isotherms more than marine species, which is probably related to the interplay between the wider thermal safety margin of terrestrial versus marine species and the more constrained physical environment for dispersal in terrestrial versus marine habitats.
\end{abstract}


40 global change driver on its own with far-reaching implications for ecosystem and human health ${ }^{5}$.

41 Managing the consequences of climate-driven species redistributions requires a better 42 understanding of the capacity of species of various taxonomic groups and from different habitats 43 to shift their distribution ranges and track shifting isotherms. As climate warms, isotherms are 44 shifting poleward and upslope to cooler latitudes and elevations in most parts of the world, 45 generating spatially-structured patterns in the velocity of isotherm shifts ${ }^{6,7}$. Marine organisms 
seem to closely track this complex mosaic of climate velocities ${ }^{8}$. However, the pattern is less clear for terrestrial organisms ${ }^{2}$. Evidence suggests that biotic responses on land are lagging behind the velocity of climate change, particularly for long-lived species and poor-dispersers ${ }^{9,10}$. To date, a comprehensive analysis of the coupling between the velocity of species range shifts and the velocity of isotherm shifts across biological systems (i.e. terrestrial vs. marine) and life forms (e.g. ectotherms vs. endotherms) is still lacking ${ }^{11,12}$.

To fill this knowledge gap, we compiled data on range shifts for marine and terrestrial species in both the northern and southern hemispheres from an exhaustive literature review building on and updating the most recent syntheses on climate-related range shifts ${ }^{2-4}$ (BioShifts ${ }^{13}$; see Data Availability for download) (Supplementary Fig. 1). The BioShifts geodatabase encompasses 30,534 range shifts documented from 258 peer-reviewed studies ${ }^{13}$, spanning a total of: 12,415 harmonized species names; four kingdoms (Bacteria, Plantae, Fungi and Animalia); 20 phyla; and 56 classes. It also contains several methodological attributes (e.g. study area, study period, sampling effort, data quality), that can be used to account for methodological variations in meta-analyses or quantitative reviews such as ours ${ }^{14}$. Based on this geo-database, we first carefully assessed the geographical and taxonomic biases ${ }^{4,15}$ impeding our knowledge of climate change effects on species redistribution (Extended Data 1-3). We then provided robust estimates of the velocity of latitudinal and elevational range shifts for the 20 most studied taxonomic classes (Fig. 1), with the aim to compare our estimates with former estimates from the existing literature ${ }^{1-3}$ while accounting for potential methodological biases ${ }^{14}$. To do so, we fitted several linear mixed-effects models (LMMs) with methodological attributes treated as random effects ${ }^{14}$, all arranged in a full factorial design of geographical gradient (latitude vs. elevation) $)^{1,2} \times$ biological system (marine vs. terrestrial) ${ }^{15} \times$ hemisphere (North vs. South $)^{4} \times$ positional parameter (centroid vs. margins) $)^{3,4}$ (Supplementary Table 1). We expected 
(1) faster velocities of latitudinal range shifts in the oceans than on land ${ }^{3}$, (2) faster velocities of range shifts in the northern hemisphere than in the southern hemisphere due to the interhemispheric asymmetry in the rate of climate warming over the twentieth century ${ }^{16}$ and (3) different velocities of shifts across the distribution range. For each taxonomic class, we thus estimated the velocity of range shift separately for the centroid and the margins of the range, making the distinction between the trailing and leading edge to test for different types of range shifts ${ }^{3,4,17,18}$ : trailing-edge contractions; leading-edge expansions; lockstep shifts involving both trailing-edge contractions and leading-edge expansions together with a displacement at the centroid of the range; and lean range shifts involving stable margins with the centroid shifting within the existing range.

Then, we assessed the coupling between the velocity of isotherm shifts and the velocity of range shifts at the species level, along the latitudinal gradient in marine systems and separately for the latitudinal and elevational gradients in terrestrial systems (Extended Data 4-6). As before, we controlled for varying methodologies ${ }^{14}$, using LMMs, and tested for two-way interaction terms between the velocity of isotherm shifts and: (i) life-form categories (ectotherms, endotherms, phanerogams, cryptogams); (ii) baseline temperatures (the historical mean annual temperature regime prior to the baseline survey); and (iii) the standardized human footprint index (a scaled variable summarizing the direct and indirect human pressures on both terrestrial and marine environments: human population density; buildings; roads; agricultural lands; pollution; commercial shipping; industrial fishing; ocean acidification; etc. ${ }^{19,20}$. Among animals, we distinguished ectotherms from endotherms to test the hypothesis that ectotherms better track shifting isotherms than endotherms. Theory and evidence suggest that ectotherms are more sensitive to temperature fluctuations than endotherms ${ }^{21}$ and conform more closely to their physiological limits of thermal tolerance, especially so for marine ectotherms ${ }^{22}$, and are thus 
94

95

96

97

98

99

100

101

102

103

104

105

106

107

108

109

110

111

112

113

114

115

116

117

more likely to closely track shifting isotherms ${ }^{8}$. For chlorophyllous organisms, we distinguished phanerogams or seed-bearing plants (angiosperms and gymnosperms) from cryptogams reproducing by spores (ferns, mosses, lichens and algae) to test the hypothesis that greater dispersal abilities in cryptogams allows to better track shifting isotherms ${ }^{23}$. As historical temperature regime may affect the rate at which species are shifting their distributions ${ }^{24,25}$, we tested whether the coupling between species range shifts and isotherm shifts varied with baseline temperatures. Similarly, we accounted for potential effects of anthropogenic disturbances on the magnitude of the coupling. We expected that land-use intensity in terrestrial systems may impede species range shifts through habitat fragmentation ${ }^{26}$, while exploitation of marine resources (e.g. demersal or bottom trawling) may accelerate the relocation of exploited stocks through massive population die-offs and crashes followed by local extinctions ${ }^{27}$.

\section{Results and discussion}

Geographical, taxonomic and methodological biases matter. We found a strong spatial imbalance in the data towards the most developed regions of the northern hemisphere (Extended Data 1-2) and a clear taxonomic bias towards the most charismatic animals (Aves, Actinopterygii, Amphibia, Mammalia) and plants (Magnoliopsida, Liliopsida) (Extended Data 3). This supports former claims that global meta-analyses on species range shifts are not truly global ${ }^{4,15}$ and that most species remain understudied, while others attract most of the public, scientific and government attention $^{28}$. In addition to these geographic and taxonomic biases, differences in methodological attributes among studies play a key role in the observed variation in the velocity of range shifts among the 12,415 species included in BioShifts ${ }^{13}$ (Fig. 2). Most of this variation was explained by methodological attributes, which contributed from 6 to $82 \%$ (mean $=36 \%$, median $=35 \%)$ of the total variation (Supplementary Table 1). By contrast, differences among taxonomic classes and positions at range margins (trailing edge vs. leading edge) contributed 
only 0 to $50 \%$ (mean $=10 \%$, median $=7 \%)$ of the total variation. These findings confirm the importance of accounting for varying methodologies in meta-analyses ${ }^{14}$. However, contrary to former meta-analyses arguing against the use of studies reporting range shifts for a single or a handful number of species because such studies are more likely to select responsive species ${ }^{1-3}$, we found no relationship between sample size and the velocity of range shifts (Supplementary Fig. 2). Hence, we recommend future meta-analyses on range shifts to consider all available information instead of constraining the analyses to the set of studies that focused on multiple species (e.g. more than 3 species).

Marine organisms move faster than terrestrial organisms. Once methodological attributes were accounted for, the variation in the estimated velocity of range shifts among taxonomic classes and positions at range margins was still fairly large, ranging from $3.20 \mathrm{~m} \cdot \mathrm{yr}^{-1}$ downslope for freshwater fishes (trailing edge, northern hemisphere) to 12.39 m.yr ${ }^{-1}$ upslope for amphibians (trailing edge, southern hemisphere) and from $6.52 \mathrm{~km} \cdot \mathrm{yr}^{-1}$ equatorward for reptiles (trailing edge, northern hemisphere) to $18.54 \mathrm{~km} \cdot \mathrm{yr}^{-1}$ poleward for insects (centroid of the range, northern hemisphere) (Fig. 3). Marine species ( $\sim 80 \%$ being ectotherms in the database, Extended Data 2 ) have moved towards the poles at a mean $\left( \pm\right.$ s.e.m.) pace of $5.92 \pm 0.94 \mathrm{~km}_{\mathrm{yr}}{ }^{-1}$ (one-sample Student's $t$-test: $t=6.26$; $d f$ residuals $=23 ; P=2.20 \times 10^{-6}$ ), almost six times faster than terrestrial species (one-way ANOVA: $\mathrm{F}=12.68 ; d f$ factor $=1 ; d f$ residuals $=45 ; P=8.88 \times 10^{-}$

$\left.{ }^{4}\right)$. This mean velocity far exceeds the one reported by the first synthesis $\left(0.61 \pm 0.24 \mathrm{~km} \cdot \mathrm{yr}^{-1}\right)^{1}$ but is very similar in magnitude and direction to the mean velocity reported by a more recent synthesis focusing exclusively on marine species $\left(7.20 \pm 1.35 \mathrm{~km} \cdot \mathrm{yr}^{-1}\right)^{3}$. Importantly, the mean velocity of latitudinal range shifts we found for terrestrial systems $\left(1.11 \pm 0.96 \mathrm{~km} \cdot \mathrm{yr}^{-1}\right)$ was nonsignificantly different from zero (one-sample Student's $t$-test: $t=1.15 ; d f$ residuals $=22 ; P=$ 0.25). This contradicts a former synthesis from 2011 reporting a mean positive velocity of 
142 latitudinal range shifts across a wide range of taxonomic groups $\left(1.76 \pm 0.29 \mathrm{~km} \cdot \mathrm{yr}^{-1}\right)^{2}$. Although 143 the authors of this synthesis chiefly focused on terrestrial taxonomic groups, they also included 144 data on range shifts from several marine taxonomic groups (molluscs and algae) in their analyses, which could explain the discrepancy. Along the elevation gradient, we found that terrestrial species have shifted upslope at a mean pace of $1.78 \pm 0.41 \mathrm{~m} \cdot \mathrm{yr}^{-1}$ (one-sample Student's t-test: $t=4.33 ; d f$ residuals $=36 ; P=1.13 \times 10^{-3}$ ), slightly faster than what was previously reported $\left(1.22 \pm 0.18 \mathrm{~m} \cdot \mathrm{yr}^{-1}\right)^{2}$.

Although we found a tendency towards faster latitudinal range shifts in the northern hemisphere $\left(4.24 \pm 0.70 \mathrm{~km} . \mathrm{yr}^{-1}\right.$; one-sample Student's $t$-test: $t=4.66 ; d f$ residuals $=36 ; P=4.28$ $\left.\times 10^{-5}\right)$ as opposed to the southern hemisphere $\left(1.07 \pm 0.34 \mathrm{~km} \cdot \mathrm{yr}^{-1}\right.$; one-sample Student's $t$-test: $t$ $=1.43 ; d f$ residuals $=9 ; P=0.19$ ), the difference was not significant (one-way ANOVA: $\mathrm{F}=$ $3.08 ; d f$ factor $=1 ; d f$ residuals $=45 ; P=0.09$ ). More data on species range shifts are thus clearly needed in the southern hemisphere (see geographical biases in Extended Data 1-2) to be able to confirm or infirm our hypothesis of faster range shifts in the northern hemisphere related to the faster rates of climate warming over there compared with the southern hemisphere ${ }^{16}$.

Regarding the position within the range, terrestrial taxa seem to have relatively stable latitudinal distributions, showing no clear signal of range shift at the trailing edge $(-0.17 \pm 1.61$ km. $\mathrm{yr}^{-1}$; one-sample Student's $t$-test: $t=-0.10 ; d f$ residuals $=5 ; P=0.92$ ), the centroid of the range $\left(2.41 \pm 2.45 \mathrm{~km} . \mathrm{yr}^{-1}\right.$; one-sample Student's $t$-test: $t=0.98 ; d f$ residuals $\left.=7 ; P=0.36\right)$ or the leading edge $\left(0.81 \pm 0.65 \mathrm{~km} . \mathrm{yr}^{-1}\right.$; one-sample Student's $t$-test: $t=1.24 ; d f$ residuals $=8 ; P=$ 0.25). By contrast, marine species seem to be very sensitive to warming, showing trailing-edge contractions $\left(6.49 \pm 2.13 \mathrm{~km} . y r^{-1}\right.$; one-sample Student's $t$-test: $t=3.04 ; d f$ residuals $\left.=7 ; P=0.02\right)$, leading-edge expansions $\left(6.02 \pm 1.77 \mathrm{~km} . \mathrm{yr}^{-1}\right.$; one-sample Student's $t$-test: $t=3.40 ; d f$ residuals $=$ $\left.8 ; P=9.32 \times 10^{-3}\right)$ and poleward shifts at the centroid of the range $\left(5.13 \pm 0.41 \mathrm{~km} . \mathrm{yr}^{-1}\right.$; one- 
166

167

168

169

170

171

172

173

174

175

176

177

178

179

180

181

182

183

184

185

186

187

188

189

sample Student's $t$-test: $t=12.54 ; d f$ residuals $\left.=6 ; P=1.57 \times 10^{-5}\right)$. Our results also indicate that the leading and trailing edge of marine species are equally sensitive to warming (one-way ANOVA: $\mathrm{F}=0.03 ; d f$ factor $=1 ; d f$ residuals $=15 ; P=0.87)$, which is consistent with expectations from thermal tolerance limits of marine ectotherms ${ }^{22}$ (though in contrast to a previous report ${ }^{3}$ ). In turn, this suggests that marine species are moving in lockstep ${ }^{4}$ towards the poles. Similarly, along elevational gradients, the trailing and leading edge of terrestrial species have moved towards the summits at a comparable mean pace of $2.34 \pm 0.67 \mathrm{~m}_{\mathrm{yr}}{ }^{-1}$ and $2.15 \pm 0.60$ m.yr ${ }^{-1}$, respectively (one-way ANOVA: $\mathrm{F}=0.03 ; d f$ factor $=1 ; d f$ residuals $=23 ; P=0.87$ ). This indicates that terrestrial species are moving in lockstep towards mountain summits, which is very consistent with two recent syntheses concluding on symmetric boundary shifts in mountains ${ }^{17,18}$. Note, however, that the mean upslope shift was significant at the leading edge (one-sample Student's $t$-test: $t=6.19 ; d f$ residuals $=12 ; P=4.65 \times 10^{-5}$ ), but only marginally significant at both the trailing edge (one-sample Student's $t$-test: $t=2.07 ; d f$ residuals $=11 ; P=0.06$ ) and the centroid of the range (one-sample Student's $t$-test: $t=2.13 ; d f$ residuals $=11 ; P=0.06$ ).

Marine species are better at tracking isotherm shifts. Assessing the degree of coupling between species range shifts and isotherm shifts (Extended Data 4-6), we found that marine species better track isotherm shifts in latitude than terrestrial species (Figs. 4-5). For marine systems, our best model explained $33 \%$ of the total variation in the velocity of species range shifts (Fig. 4a). Only $4 \%$ of the total variation was related to fixed effects, namely the velocity of isotherm shifts (VIS), standardized human footprint index (HFI), baseline temperatures (BT), life forms (LF) and synergistic effects between VIS and HFI or BT (Fig. 4b), whereas $29 \%$ was explained by random effects or methodological attributes (Supplementary Table 2). Again, this strongly supports the idea that varying methodologies in estimates of climate-driven biological responses can contribute to most of the explained variation and need to be explicitly considered in quantitative 
reviews ${ }^{14}$. Noteworthy, we found that faster climate velocities combined with higher human pressures in the oceans (e.g. commercial shipping, industrial fishing, ocean acidification) or warmer sea surface temperatures during the baseline survey increases the velocity of species range shifts along the latitudinal gradient for both marine ectotherms and cryptograms (Figs. 5cd, Extended Data 7, Supplementary Table 2). More specifically, we found that marine species closely track shifting isotherms either in initially warm and undisturbed waters (e.g. Central Pacific Basin) ${ }^{19}$ or in initially cold waters where human activities are more pronounced (e.g. Norwegian Sea, North Sea and English Channel) (Fig. 6c, Extended Data 8). This pattern is unlikely to result from a collinearity issue between the velocity of isotherm shifts and the standardized human footprint index $\left(\mathrm{R}^{2}=0.05\right)$ (Supplementary Fig. 3). Instead, it may stem from the combination of two processes. First, marine species are living closer to their upper thermal limits in the tropics, where sea surface temperatures are the highest, thus increasing the likelihood of local extirpations at their trailing edges as climate warms ${ }^{11}$. Second, lower constraints on dispersal and colonization in the oceans (as opposed to terrestrial habitats) ${ }^{3}$ may help species to rapidly shift their distribution towards the newly available habitats. By contrast, at high latitudes where the thermal safety margin of marine species is larger ${ }^{11}$, climate warming alone is unlikely to explain isotherm tracking. Instead, anthropogenic activities (e.g. fishing pressure and pollution in the North Sea) may render populations more sensitive to climate change by reducing abundance and density, truncating the age distribution and leading to the depletion of fish stock at the trailing edge of their range ${ }^{27}$. In parallel, successful management actions at higher latitudes, such as along the Norwegian's coastlines in the Norwegian Sea and the Barents Sea, combined with climate warming, may increase population sizes of commercial fishes at the leading edge of their range ${ }^{29}$, thus promoting successful colonization. 
214 and the velocity of isotherm shifts is comparatively poor on land (Fig. 4). Again, this

215 inconsistency with a former synthesis ${ }^{2}$ from 2011 may stem from the fact that we here analyzed

216 the coupling separately for the marine and terrestrial systems, a distinction that was not possible

217 in 2011 due to a lack of data at that time, for marine systems. Our best model explained $47 \%$ of

218 the total variation in the velocity of species range shifts along the latitudinal gradient on land 219 (Supplementary Table 2), of which the largest proportion was explained by varying

220

221

222

223

224

225

226

227

228

229

230

231

232

233

234

235

236

methodologies among studies (Fig. 4a). Among fixed effects, we found that range shifts were best explained by differences between life forms and a negative interaction term between the velocity of isotherm shifts and the standardized human footprint index (explaining $8 \%$ of the total variation; Fig. 4b). Such antagonistic effect between climatic and human-related drivers suggests that habitat loss and fragmentation - associated with high population densities and other human activities such as agricultural practices - in the lowlands, combined with limited species' dispersal abilities - relative to the speed at which isotherms are shifting along the latitude gradient $^{30}$ - likely impede the capacity of terrestrial taxa to track shifting isotherms. Again, this pattern is unlikely to result from a collinearity issue between the velocity of isotherm shifts and the standardized human footprint index $\left(\mathrm{R}^{2}=0.09\right)$ (Supplementary Fig. 3). Interestingly, we found that when exposed to a high degree of anthropogenic disturbances $(H F I>0.3)$, terrestrial species tend to shift in the opposite direction to isotherms (i.e. HFI conditions for which both velocities show opposite signs in Fig. 5b and Extended Data 9), most likely due to local extinction processes at the leading edge. For instance, a previous study showed that during 19701999, habitat loss and degradation led to a decline in the distribution sizes of three-quarters of butterfly species that approach their northern climatic range margins in Britain, outweighing the climate-induced species range shifts that were expected from climate warming ${ }^{26}$. This is 
consistent with the general idea that land-use and climate change may act as opposing forces on species distribution changes. In addition, air conducts heat 25 times less effectively than water ${ }^{12}$, which makes terrestrial species, in general, less sensitive than marine species to temperature fluctuations and thus less likely to move as a direct response to climate warming ${ }^{11}$. The availability of thermal microrefugia (e.g. shaded environments) on land may also allow species to more easily regulate their body temperature (e.g. microhabitats may allow terrestrial ectotherms to increase their thermal safety margin by $3{ }^{\circ} \mathrm{C}$ on average as compared with marine ectotherms ${ }^{11}$ ). Hence, we confirm that isotherm tracking is very unlikely for terrestrial taxa living in the lowlands ${ }^{9,25}$.

Along elevational gradients, the best model explained $11 \%$ of the total variation in the velocity of range shifts (Fig. 4a; Supplementary Table 2) and showed that the velocity of isotherm shifts interacts with both baseline temperatures and life forms (explaining $2 \%$ of the total variation; Figs. 5a-6a, Extended Data 9-10). Contrary to the latitudinal gradient, the standardized human footprint index was not selected as a meaningful explanatory variable in the best model. Noteworthy, we found a better coupling between the velocity of species range shifts and the velocity of isotherms shifts for ectotherms in cold environments (i.e. close to mountaintops). The geographic isolation and habitat area constraints specific to mountaintops (e.g. sky islands) may exacerbate local extinction events through reduced population sizes as climate warms and habitat area shrinks, thus paying off part of the climatic debt for ectotherms living close to mountaintops. For instance, mass extinction events associated with climate warming and pathogen outbreaks have already been reported for several amphibian species endemic to mountainous regions ${ }^{31}$. For endotherms, phanerogams and cryptogams, the slope of the relationship between the velocity of species range shifts and the velocity of isotherm shifts in mountainous systems is negative, especially under warm climates (Extended Data 9). However, 
we found that velocity values for range shifts along elevational gradients are always positive, except under very warm baseline temperature conditions $\left(B T>20^{\circ} \mathrm{C}\right)$. This indicates that endotherms, phanerogams and cryptogams are in general shifting their elevational ranges upslope to track shifting isotherms but are consistently lagging behind climate change. Isotherms may be shifting upslope at a pace that is simply too fast for species with limited dispersal abilities and long life spans, such as trees, to keep pace. Additionally, in the tropics, the higher importance of biotic interactions ${ }^{32}$ may further impede the rate of range shifts over what is expected from climate change alone ${ }^{33}$. But most importantly, the global climatic grids that are currently available, and that we used here, may still be too coarse in spatial resolution $\left(1 \mathrm{~km}^{2}\right.$ at best) to allow a reliable assessment of the true velocity of isotherm shifts experienced along mountain slopes. Indeed, the topoclimatic and microclimatic heterogeneity that is available across few metres in mountain systems, something that is not accounted for here, may provide a strong spatial buffer against climate warming ${ }^{34}$, allowing species to shift at relatively small spatial distances and seemingly "stay" 35 relative to the velocity of isotherm shifts that is measured at a coarser spatial resolution. Hence, the slow velocities of species range shifts that we observed in mountainous areas could also be the result of local compensation effects involving short distance escapes and species persistence within microrefugia.

General implications. To conclude, the coupling between species range shifts and isotherm shifts is not uniform across biological systems, confirming the lags observed in the biotic responses of terrestrial organisms to climate change ${ }^{9,10}$. Noteworthy, we demonstrate complex interactions between the velocity of climate warming, the degree of human pressures on the environment, historical temperature regimes and species characteristics. We suggest that commercial fishing may speed up the displacement of marine species distribution through resource depletion and population crashes at the trailing edge, whereas low constraints on 
285

286

287

dispersal in the oceans may allow marine species living close to their upper thermal limits to better track climate warming at the leading edge. On land, habitat loss and fragmentation due to land-use changes may impede the ability of terrestrial species to track shifting isotherms. These complex interactions need to be accounted for to improve scenarios of biodiversity redistribution and its consequences on human well-being ${ }^{5}$ under future climate change. The fact that marine species better track climate warming than terrestrial species also suggests that biodiversity redistribution will have more immediate and far-reaching consequences in the oceans than on land. For instance, community reshuffling ${ }^{9,25}$ and the "tropicalisation" of temperate ecosystems ${ }^{36,37}$ is likely to happen much faster in marine than in terrestrial systems, with more direct and rapid consequences on ecosystem health and functioning (e.g. increasing fish herbivory in kelp forests ${ }^{38}$ ) as well as on the valuable services (e.g. fishery) and disservices (e.g. coastal erosion) oceans can provide.

However, it is important to bear in mind that our findings, as well as former syntheses on the topic, are still dependent on data availability and thus suffer from severe taxonomic and geographic biases. Despite a broad taxonomic coverage of the tree of life (Extended Data 3), species range shifts recorded in BioShifts ${ }^{13}$ cover only $0.6 \%$ of the described biodiversity on Earth $(\mathrm{N}=2,094,892$ taxa). Besides, it is noteworthy that species range shifts in the southern hemisphere and in tropical regions in general are underrepresented. These limitations may affect our perception of species redistribution, and by consequence challenge global biodiversity conservation efforts ${ }^{4,15}$. It is thus more important now than ever to continue to study and document range shifts in areas and for taxonomic groups that have been so far somewhat neglected. Our database on species range shifts provides solid foundations to build a truly global monitoring of species redistribution. We thus call for future research perspectives linking our 
308 database on species range shifts with existing but scattered databases on species traits ${ }^{39-44}$ to 309 improve our ability to anticipate biodiversity redistribution under climate change. 
Literature search. We reviewed the scientific and peer-reviewed literature reporting climatedriven range shifts under contemporary climate change. By contemporary climate change, we here mean the period stretching from the beginning of the 19th century and onwards. As a general approach, we started from the reference lists of the most recent meta-analyses and syntheses on the topic ${ }^{2-4}$ that we completed by regularly searching the scientific literature published between 2014 and 2018, following the same protocol as in Lenoir \& Svenning ${ }^{4}$ (Supplementary Fig. 1). Because of the clear focus on latitudinal and elevational range shifts in the scientific literature and the lack of information on the other geographical dimensions ${ }^{4}$, we excluded several reports focusing exclusively on bathymetric or longitudinal range shifts. Broad inclusion criteria comprised studies: (i) focusing on relatively recent (since 1850s) distribution changes; (ii) based on occurrence or abundance data of at least one species; and (iii) only if studies were based on assessments covering at least two historical censuses with a minimum of 10 years between censuses. Hence, we excluded studies reporting distribution range changes from a single census (synchronous approach comparing data from different ontogenetic life stages of the same species like seedlings vs. adult trees) or based on historical patterns of species mortality obtained from climatic reconstructions only, without real occurrence or abundance data from at least two different time periods to confirm model outputs. We also excluded studies focusing exclusively on distributional range changes of invasive alien species. This selection procedure led to a total of 258 published and peer-reviewed studies for which we could extract data on species range shifts ${ }^{8,27,45-300}$.

We used Google Sheets to store the raw data on species range shifts in a dynamic and common file that we shared among co-authors, while always keeping a regular copy of the database saved on several computers to ensure backups. Once studies were clearly identified and 
stored as “.pdf” files in a common folder in Google Docs, each co-author picked studies, one by one, and entered data manually in the database. Some of the ".pdf" files were carefully annotated to help us quickly identify and recover any meaningful information in the main text or display items (e.g. tables or figures). When data on species range shifts were not directly available in the main text, in tables or in the appendices of the publication, we first contacted the corresponding authors and requested the data. In case of no positive response from the original authors and when data on range shifts could be extracted from published figures, we used the "WebPlotDigitizer" program (https://automeris.io/WebPlotDigitizer/). When range shifts were reported for more than one geographically distinct survey area or between more than two censuses (e.g. more than one resurvey of historical data), we considered them as independent case studies $(\mathrm{N}=325)$. This data entry procedure led to a total of 30,534 range shift estimates at the species level (see Data Availability to access the database: BioShifts ${ }^{13}$ ).

Range shift estimates, as reported by the original authors, were coded as positive values if poleward in latitude, or upward in elevation, and negative otherwise (equatorward and downward). When the authors reported horizontal range shifts with both the magnitude and direction (i.e. azimuth) values, we used trigonometric relationships to transform these values into latitudinal range shifts for consistency with the main bulk of data available in the scientific literature. Next, we divided each range shift estimate by the study duration between two consecutive censuses (ending year - starting year +1 ) to assess the rate or velocity of range shift (ShiftR), in kilometer per year along the latitudinal gradient and in meter per year along elevational gradients. In addition to the velocity of range shift at the species level, we also retrieved information at the case study level $(\mathrm{N}=325)$, including methodological attributes known to potentially affect the velocity of range shift ${ }^{14}$ : the starting year of the study (Start); the ending year of the study (End); the size of the study area (Area); the number of taxa in a study 
358 (Ntaxa) (continuous variable ranging from 1 to 4426 ; median $=21$; mean $=122)$; the frequency

359 of sampling (Sampling) (factor variable with four levels: "continuous"; "irregular"; or

360 comparison of "two"; or "multiple" periods); whether range shift estimates were generated from

361 "occurrence" or "abundance" data (PrAb) (factor variable with two levels); the spatial resolution

362 of the raw data used to estimate range shifts (Grain) (factor variable with three levels: "fine" for

363 data based on GPS coordinates with a spatial resolution lower than $10 \mathrm{~km}$; "coarse" for data

364 based on range maps or atlas grids with a spatial resolution greater than $100 \mathrm{~km}$; and "medium"

365 for intermediate situations); the quality of the approach used to estimate range shifts (Quality)

366 (factor variable with four levels: "low" when no data cleaning procedures were performed before

367

368

369

370

371

372

373

374

375

376

377

378

379

380

381 computing range shifts; "balanced" when data cleaning or resampling procedures were carried out to calculate range shifts on a balanced dataset; "modeled" when range shifts were obtained by computing the difference in the position of a given range parameter estimated from species distribution models (SDMs) independently calibrated during at least two different time periods (note that in this case SDM outputs represent the realized and not the potential species distribution for a given time period); and "resurveyed" when range shifts were calculated from paired designs such as permanent plots); and whether the "significance" of range shift estimates were assessed or "not" in the original study (Signif) (factor variable with two levels). To improve the balance in the number of observations among levels of a given factor variable, we merged some levels with poor data coverage together for the Sampling and Quality variables. For instance, the levels "continuous" and "irregular" were merged together with the level "multiple" such that Sampling was used in our analyses as a factor variable with two levels: "two" vs. "multiple". Regarding the Quality variable, we merged the level "resurveyed" together with the level "balanced" such that Quality was used in our analyses as a factor variable with three levels: "low"; "balanced"; and "modeled". Still at the case study level $(\mathrm{N}=235)$, we digitized the study 
382

383

384

385

386

region in Google Earth and used the resulting polygons to retrieve spatial information such as the total area covered by the study. If no clear maps delineating the study area was reported in the original study (e.g. map displaying the study region), we used national geographic boundaries or any meaningful spatial information from the text to delineate the study area. All spatial polygons were used to produce a geo-database (Extended Data 1-2).

Taxonomic harmonization. Before undertaking any taxonomic harmonization procedure, the last version of our database, dated April 2018, contained 13,570 entries of taxa at any taxonomic rank up to the genus level (i.e. subspecies, species and genus). Using the $\mathrm{R}$ programming $\operatorname{language}^{301}$, we assembled an $\mathrm{R}$ script in order to retrieve, for each taxonomic entry, the most recent accepted name and its associated classification. After a visual inspection for obvious syntax correction, three steps of taxonomic verification were performed. First, names were searched in the National Center for Biotechnology Information (NCBI) taxonomy database using the function "classification" from the R package "taxize"302. Then, in the same way, any remaining taxonomic entity not found in NCBI was verified with the Integrated Taxonomic Information System (ITIS) database. The full taxonomic classification was also retrieved during these two steps. Third, the last remaining taxonomic entities not found in NCBI and ITIS were checked using the Global Biodiversity Information Facility (GBIF) database, using the function "name_backbone" in the R package "rgbif". If we found a match, the corrected taxonomic entity was again checked in NCBI and ITIS by undergoing the previously mentioned procedure once again to retrieve a reliable taxonomic classification. Finally, only names at the species and the genus level were kept for the analyses (subspecies being aggregated at the species level). Following this taxonomic harmonization procedure, the final number of taxa names in the database was reduced to 12,415 . 
Climate velocity. Using the spatial information obtained from the digitized polygons as well as the temporal information (Start and End years) available from each of the 258 publication sources, we retrieved basic temperature information to calculate the velocity of temperature change throughout the study period. Terrestrial climate data were obtained from WorldClim v. 1.4 (http://www.worldclim.org/) and the Climate Research Unit (CRU) TS v. 3.23 (https://crudata.uea.ac.uk/cru/data/hrg/) while marine climate data were obtained from BIOORACLE (http://www.bio-oracle.org/) and the Met office Hadley Centre observations datasets (https://www.metoffice.gov.uk/hadobs/hadisst/).

Because marine and terrestrial taxa shift at different rates and directions to potentially track the complex mosaic of local climate velocities ${ }^{8}$, we calculated the observed local velocity of temperature change (i.e. the spatial shift of isotherms over time) $)^{6,7}$ for each case study, following the approach used by Burrows et al. ${ }^{7}$. We divided the temporal change in annual mean temperature observed over the studied period $\left({ }^{\circ} \mathrm{C} \cdot \mathrm{yr}^{-1}\right)$ by the corresponding spatial gradient $\left({ }^{\circ} \mathrm{C} \cdot \mathrm{km}^{-1}\right.$ or $\left.{ }^{\circ} \mathrm{C} \cdot \mathrm{m}^{-1}\right)$ as a measure of the velocity of temperature change $\left(\mathrm{km}_{\mathrm{gr}} \mathrm{rr}^{-1} \text { or m.yr }{ }^{-1}\right)^{6}$. The temporal gradient was calculated using time-series data from the CRU covering the period 19012016 at a spatial resolution of $0.5^{\circ}$ (about $55 \mathrm{~km}$ at the equator) and from the Met office Hadley Centre observations datasets covering the period 1870-2018 at a spatial resolution of $1^{\circ}$ (about $111 \mathrm{~km}$ at the equator) for terrestrial and marine studies, respectively. To do so, we regressed annual mean temperature $\left({ }^{\circ} \mathrm{C}\right)$ values for all years throughout the study period as well as the two preceding years against time (yr) using linear regressions. When the starting year was prior to 1901 or 1870 for terrestrial and marine systems, respectively, we started the time series in 1901 or 1870 depending on the climate series. The slope parameter $\left({ }^{\circ} \mathrm{C} \cdot \mathrm{yr}^{-1}\right)$ of this model was then used as an estimate of the temporal gradient. For the sake of comparison with the rate of range shift usually calculated along the latitudinal and elevational gradients, we calculated the spatial 
gradient of annual mean temperature along the latitudinal $\left(\mathrm{km}_{\mathrm{yr}} \mathrm{yr}^{-1}\right)$ and along elevational $\left(\mathrm{m} \cdot \mathrm{yr}^{-1}\right)$ gradients, separately. This allowed us to assess both the latitudinal and elevational velocity of temperature change (LatVeloT and EleVeloT). To assess the latitudinal spatial gradient of annual mean temperature across land and sea, we used spatial grids from WorldClim and BIOORACLE, respectively, at a spatial resolution of 5 arc-minute (about $9.2 \mathrm{~km}$ at the equator). The WorldClim grid of annual mean temperature was downloaded at the finest spatial resolution, which is 30 arc-second (about $1 \mathrm{~km}$ at the equator), but aggregated at 5 arc-minute to be consistent with the spatial resolution of sea surface temperatures. Latitudinal spatial gradients were calculated as in Burrows et al. ${ }^{7}$ based on a $3 \times 3$ neighborhood sub-grid with the centre cell being the focal cell and its eight neighboring cells used to calculate the difference in temperatures for each northern and southern (resp. southern and northern in the southern hemisphere) pairs divided by the distance between them. Average differences $\left({ }^{\circ} \mathrm{C} \cdot \mathrm{km}^{-1}\right)$ for the focal centre cell were calculated, excluding any missing values (usually along coastlines), using weightings of 1 and 2 for cells diagonal and adjacent, respectively, to the focal centre cell. For the elevation gradient, we used the temperature data from the WorldClim grid of annual mean temperature at the finest spatial resolution (30 arc-second which is about $1 \mathrm{~km}$ at the equator) and calculated the spatial gradient across each case study using a linear model relating annual mean temperature (the response variable) to both elevation and latitude (the explanatory variables). We used latitude as a covariate in this model to account for the latitudinal variation in temperature observed within studies covering large spatial extents, i.e. elevation values close to the equator are not directly comparable, in terms of temperature, to elevation values close to the poles. The coefficient parameter along elevational gradients $\left({ }^{\circ} \mathrm{C} \cdot \mathrm{m}^{-1}\right)$ was then used as an estimate of the local adiabatic lapse rate. For the study areas that were larger in extent than the spatial resolution of the temperature grids, we computed the mean values of LatVeloT or 
453 EleVeloT throughout the entire study area by averaging values across all spatial grid cells

454 overlapping with the polygons delineating the study area.

455 Additional drivers of range shifts. As baseline temperature conditions may affect the rate at 456 which species are shifting their distributions ${ }^{24}$, we extracted annual mean temperature values 457 during the year of the initial census (Start) as well as the two preceding years and calculated the mean (hereafter $B T$ in ${ }^{\circ} \mathrm{C}$ ). For terrestrial and marine systems, we used time-series data from CRU and the Met office Hadley Centre observations datasets, respectively. When the initial census of a given publication source was prior to 1901 or 1870 for terrestrial and marine systems, respectively, we used the oldest years available from the time series to compute baseline temperature conditions. Similar to climate velocity variables, when the study areas were larger in extent than the spatial resolution of the temperature grids, we computed the mean values of $B T$ throughout the entire study area by averaging values across all spatial grid cells overlapping with the polygons delineating the study area.

As anthropogenic disturbances such as land-use intensity or industrial fishing may act as confounding factors on the velocity of range shift ${ }^{24}$, we retrieved information on anthropogenic impacts for both the terrestrial and marine environment. For terrestrial systems, we downloaded the Global terrestrial Human Footprint maps for the year $2009^{20}$. These maps, at a spatial resolution of 30 arc-second (about $1 \mathrm{~km}$ at the equator), provide remotely-sensed and bottom-up survey information on eight variables measuring the direct and indirect human pressures on the environment: (1) the extent of built environments; (2) human population density; (3) electric infrastructure (night-light time); (4) crop lands; (5) pasture lands; (6) roads; (7) railways; and (8) navigable waterways acting like roads for people to access natural resources. All eight pressure variables were scaled by the original authors based on their degree of influence on the terrestrial environment. For instance, human population density and night-time lights were scaled between 
0 and 10 while roads were scaled between 0 and 8 . Scores for each of the eight individual threats were then summed and weighted by the original authors to make a composite map of the global human footprint index ranging from 0 to 50. For marine systems, we used the Global Map of Human Impact on Marine Ecosystems ${ }^{19}$, also available at 30 arc-second resolution (about $1 \mathrm{~km}$ at the equator). This gridded dataset provides a cumulative impact score ranging from 0.01 to 90.1 for the minimum and maximum value, respectively. It was developed on the basis of expert judgment, to estimate ecosystem-specific impacts with respect to 17 anthropogenic drivers of ecological change (e.g. commercial shipping, demersal and pelagic fishing, ocean acidification, pollution). To allow comparison between terrestrial and marine systems, we rescaled both indices between 0 and 1 (standardized human footprint index or standardized HFI) and computed the mean per study area. The original authors have extensively validated HFI values against satellite imagery, yielding high confidence they represent conditions of human pressure on the environment ${ }^{20}$.

Description: assessing geographic and taxonomic biases. To evaluate spatial biases in the reporting of species range shift, we built $2^{\circ} \times 2^{\circ}$ gridded maps, on top of which we overlaid the digitized polygons associated with the observations gathered in the database for both the terrestrial and marine realm, and separately for latitudinal and elevational range shifts. For each $2^{\circ} \times 2^{\circ}$ grid cell, we also computed the relative proportion of ectotherms vs. endotherms for animals and phanerogams vs. cryptogams for plants and plant-like life forms (e.g. lichens and algae). We distinguished ectotherm from endotherm life-forms due to their contrasting sensitivity to temperature fluctuations in the environment, with ectotherms being unable to directly regulate their body temperatures as opposed to endotherms. The distinction between phanerogams and cryptogam life-forms allowed to contrast between two different reproduction strategies among chlorophyllous organisms: the evolved seed-bearing plants (angiosperms and gymnosperms) vs. 
the other plant-like life forms reproducing by spores (ferns, mosses, lichens and algae). We then generated cartograms using the diffusion-based method for producing density-equalizing $\operatorname{maps}^{303}$. The number of range shift rates per $2^{\circ} \times 2^{\circ}$ grid cell (i.e. sample size) was used to distort the map: the bigger the grid cell, the larger the sample size (Extended Data 1). We additionally estimated the phylogenetic coverage of the range shift database with respect to the whole tree of life described in the Open Tree of Life (https://tree.opentreeoflife.org) collapsed at the level of taxonomic classes and the total number of species recorded in the Catalogue of Life (http://catalogueoflife.org)).

Detection: estimating the velocity of range shifts per taxonomic class. Data coverage in our database is very unbalanced between: the marine vs. terrestrial realm; the northern vs. southern hemisphere; and the margins vs. centroid of the species range (Supplementary Table 1). Besides, data on species range shifts do not even exist for some taxonomic classes in some of the combination of realm $\times$ hemisphere $\times$ position in the species range. For instance, dicots (Magnoliopsida) are exclusively terrestrial organisms while cartilaginous fishes (Chondrichthyes) almost exclusively live in marine habitats except for a few sharks and rays living in freshwater habitats during all or part of their lives. Thus, a single model to estimate the velocity of range shifts per taxonomic class while accounting for methodological biases ${ }^{4,14,15}$ would be inappropriate. Hence, we divided latitudinal range shifts $(\mathrm{N}=16,952)$ into a full factorial design ${ }^{304}$ with eight experimental units based on all possible combinations of levels across three factor variables: biological system (marine vs. terrestrial); hemisphere (north vs. south); and range position (centroid vs. margins). We did the same for elevational range shifts ( $\mathrm{N}$ $=13,582$ ) except that there were only four possible experimental units (i.e. terrestrial systems only). To ensure robust fit, we further focused on taxonomic classes with more than 30 observations per experimental unit $(\mathrm{N}=20$ taxonomic classes fulfilling this sample size 
criterion) (Fig. 1, Supplementary Table 1), which reduced our sample size to 16,399 and 13,341 observations for latitudinal and elevational range shifts, respectively. Among the 12 possible combinations, only one combination (latitude $\times$ margins $\times$ terrestrial $\times$ south) could not be fulfilled due to a lack of range shift data $(\mathrm{N}=8)$. This resulted in a total of 11 sub-models (i.e. factorial models) (Supplementary Table 1).

For each of the 11 factorial models for which the data were available, we built a linear mixed-effects model (LMM) relating the velocity of species range shift (ShiftR) for a given taxon (i.e. the response variable) against taxonomic Class, a factor variable with as many levels as the number of taxonomic classes within the focal experimental unit (e.g. Amphibia vs. Aves for latitudinal range shifts at the centroid of the distribution in terrestrial systems of the southern hemisphere) (Supplementary Table 1). Note that if a given factorial model only had data for one unique taxonomic class (e.g. Actinopterygii for latitudinal range shifts at the centroid of the distribution in marine systems of the southern hemisphere) (Supplementary Table 1), then the variable Class was not included in the fixed effects of the LMM. For the five LMMs focusing on the rate of range shift at the margins of the distribution, we added an extra factor variable (Margin) with two levels ("leading" vs. "trailing" edge) in the fixed effects, to provide robust estimates of the rate of range shift at both the leading and trailing edges. Given the complex structure of the database, involving repeated observations per taxonomic units (e.g. family, genus) or methodological levels, LMM is the most appropriate modelling approach ${ }^{304}$. This allowed to provide estimates of the velocity of range shifts per taxonomic class that are representative across all levels of a given methodological variable rather than providing estimates for each level separately, while accounting for taxonomic non-independence. More specifically, we included Genus as a random intercept term nested (or not: in case of singularity fit) within Family to account for potential taxonomic autocorrelation in the residuals of the 
models. In addition, because the different methodological approaches used in the scientific studies may also contribute to a non-negligible fraction of the variation in range shifts ${ }^{14}$, we considered several methodological variables as random intercept terms in the LMMs (Area, Start, Ntaxa, Sampling, PrAb, Grain, Quality and Signif). To be included in the random part of our LMMs, the continuous variables Area, Start and Ntaxa were first transformed into factor variables with four levels each, using the respective quantiles as cutting points. Then, for each factorial model separately, we selected only the set of uncorrelated variables with at least two levels having more than four observations. We used the "Imer" function from the "Ime4" package $^{305}$ in the $\mathrm{R}$ programming language $\mathrm{e}^{301}$.

We used a model selection procedure where the best random effect structure was identified by testing all the combinations of random factors and selecting the one with the lowest Akaike information criterion with small-sample correction (AICc). To compare AICc values among candidate models, we set the restricted maximum likelihood argument to "FALSE" in the "Imer" function (i.e. REML $=$ FALSE for maximum likelihood) ${ }^{305}$. To ensure robust estimations, all the singular fits were removed from the list of candidate models prior to model selection. In case of singular fits across all candidate models, we used case study (Source) as the unique random intercept term. If the random intercept term Source also led to a singular fit, then we used a linear regression model (LM). For each of the LMMs (or LMs in case of singular fits for all the candidate models) focusing on the velocity of range shift at the margins of the distribution, we also included an interaction between Margin and Class that we tested against a model without the interaction term in the fixed effects based on the AICc value. When the absolute difference in AICc value between these two candidate models was greater than two, we selected the model with the lowest AICc value. Otherwise, in case of equivalent competing models, we selected the one with the interaction effect between Margin and Class considering that it allows flexible 
range shift estimations at the trailing and leading edge. Once the best LMM was selected for each factorial model (Supplementary Table 1), we set REML to TRUE ${ }^{305}$ to extract coefficient estimates among the different levels of the factor variables Class and Margin. To test whether the estimated rate of range shift for a given taxonomic class and at a given position within the range was significantly different from zero, we reran each of the 11 selected best models using a bootstrap approach $(\mathrm{N}=5,000$ iterations $)$. From these 5,000 estimates, we computed the mean and median velocity of range shift as well as the standard deviation and 95\% confidence interval per taxonomic class. Finally, to assess the overall goodness-of-fit of the different factorial models, as well as to compare the relative importance of biological versus methodological effects on the rate of range shift, we computed the marginal (i.e. variance explained by the fixed effects) and conditional (i.e. variance explained by both the fixed and random effects) $\mathrm{R}^{2}$ values ${ }^{306}$ of each bootstrap iteration and for each factorial model using the "r.squaredGLMM" function from the "MuMIn" package in the R programming language ${ }^{301}$.

Attribution: coupling between species' range shifts and isotherms' shifts. We assessed the coupling between the velocity of species range shifts and the velocity of isotherm shifts (VIS) using LMMs built separately for the latitudinal and elevational gradients. We specified the velocity of species latitudinal $\left(\mathrm{km}_{\mathrm{yr}} \mathrm{y}^{-1}\right)$ or elevational $\left(\mathrm{m} \cdot \mathrm{yr}^{-1}\right)$ range shifts as the response variable and either the latitudinal or elevational VIS (LatVeloT / EleVeloT; continuous variables) as the main explanatory variable. To account for potential interacting effects on the relationship between the velocity of range shifts and VIS, we added several covariates in our models: baseline temperature (BT; a continuous variable); standardized human footprint index (standardized HFI; a continuous variable representing human pressures on the environment bounded between 0 and 1); and life forms (LF) (a factor variable with 4 levels: ectotherm, endotherm, cryptogam, phanerogam). As temperature regimes and human pressures on the environment are not directly 
comparable between lands and oceans, we further modeled the coupling between the velocity of species latitudinal range shifts and VIS in latitude (LatVeloT) separately for the marine and terrestrial realm. We tested for all two-way interaction terms between each covariate (BT, HFI and LF) and VIS (either LatVeloT or EleVeloT). We also tested for a unimodal relationship between the estimated rates of range shifts and baseline temperature conditions (BT) using a second-order polynomial term. The variables Position within the range (a factor variable with 3 levels: trailing edge, centroid and leading edge) and Hemisphere (a factor variable with 2 levels: North vs. South) were not incorporated as covariates in the models as both variables had no effect to explain the variation in the rates of latitudinal and elevational range shifts per taxonomic class (Supplementary Table 2).

Similar to the LMMs developed at the taxonomic class, the aforementioned explanatory variables were used as fixed effects in LMMs, whereas the methodological attributes (Area, Start, Ntaxa, Sampling, PrAb, Grain, Quality and Signif) were used as random intercept terms. Starting from the beyond optimal model (full model with all fixed effects) ${ }^{305}$ separately for the velocity of latitudinal range shifts in marine and terrestrial systems as well as for the velocity of elevational range shifts, we tested all model combinations and selected the best model based on the lowest AICc value, setting REML to FALSE (i.e. maximum likelihood) for model selection and then to TRUE to estimate the coefficients once the best model was selected ${ }^{305}$. We first selected the random effect structure after removing singular fits, using the exact same procedure as for the models used to estimate the mean velocity of range shift per taxonomic class. We then selected the fixed effect structure, keeping the previously identified random structure constant. All continuous variables (LatVeloT, EleVeloT, BT and HFI) were standardized to z-scores using the "gscale" function ${ }^{307}$ from the "jtools" package in the R programming language ${ }^{301}$. This function standardizes each value of a given variable by subtracting it from the mean and dividing 
621 it by two times the standard deviation of the focal variable (instead of one time as more

622 commonly done). This rescaling formula is recommended over the traditional formula of dividing by one time the standard deviation because it allows direct comparisons of model coefficients with untransformed binary predictors ${ }^{307}$. For the sake of consistency, we focused on the set of species belonging to the taxonomic classes with more than 30 observations, resulting in 16,521 (1,403 marine vs. 15,118 terrestrial) and 13,459 observations for latitudinal and elevational range shifts, respectively. The $95 \%$ confidence intervals around each of the estimated coefficients were calculated using bootstraps $(\mathrm{N}=5,000$ iterations), similar to the models used to estimate the mean velocity of range shift per taxonomic class.

Finally, to illustrate the capacity of species to track the shifting isotherms, we mapped the predicted slopes for each combination of the predictors identified in the best models, separately for latitudinal (marine or terrestrial) and elevational range shifts. A slope value of one between the velocity of species range shifts and the velocity of isotherm shifts indicates a perfect coupling with species closely tracking the shifting isotherms. To do so, we built a $2^{\circ} \times 2^{\circ}$ gridded map, on top of which we overlaid the digitized polygons associated with each observation used in the previous models. We then generated cartograms using the diffusion-based method for producing density-equalizing maps ${ }^{303}$. As before (see section entitled "Detection: assessing geographic and taxonomic biases"), the number of range shift rates per grid cell (i.e. sample size) was used to distort the map: the bigger the grid cell, the larger the sample size. Finally, we tested whether the slope estimated for each $2^{\circ} \times 2^{\circ}$ grid cell (i.e. according to the grid-specific baseline temperature and the standardized human footprint index) significantly differed from a value of one (indicating a perfect coupling), based on 5,000 bootstrap iterations. 
644 645 646 647 648 649 650

JL, LC, JM and GG initiated and conceived the project idea. LC and JL built the general structure of the database. GG, LC, RB, TH and JL reviewed the scientific literature and filled the database throughout the project duration. GG ensured data curation. LB and LC carried out the taxonomic harmonization of the database with help from JM. TH linked the taxonomic backbone of the database to the Open Tree of Life (https://tree.opentreeoflife.org) and to Catalogue of Life (http://catalogueoflife.org/) to produce a visualization of the phylogenetic coverage of the database. GG, LC, JL and RB prepared the set of methodological variables included as covariates in the subsequent analyses. RB and JL analyzed the data with help from LC, LB and GG. TH, RB and JL produced all the figures. JL wrote the manuscript with contribution from all co-authors. JL and RB contributed equally to this work.

The data supporting the findings of this study are available in the BioShifts geo-database in the Figshare Digital Repository ${ }^{13}$ available at https://figshare.com/s/ebd19485a00757ababb0

\section{Code Availability}

$\mathrm{R}$ scripts used in the analyses are available at https://figshare.com/s/ebd19485a00757ababb0

\section{Acknowledgments}

We acknowledge authors who kindly sent us their data on species range shifts estimates. In particular, we are thankful to Kristin Kleisner and Christopher Hassall who kindly provided data on behalf of the NOAA Northeast Fisheries Science Center, The Nature Conservancy, the British Arachnological Society and the Spider Recording Scheme. Finally, we wish to acknowledge 
664 several grants from the Agence Nationale de la Recherche (TULIP ANR-10-LABX-41, CEBA 665 ANR-10-LABX-25-01).

\section{Competing Interests Statements}

667 Authors declare no competing interests. Reprints and permissions information is available at 668 www.nature.com/reprints 
670

671

672

673

674

675

676

677

678

679

680

1. Parmesan, C. \& Yohe, G. A globally coherent fingerprint of climate change impacts across natural systems. Nature 421, 37-42 (2003).

2. Chen, I.-C., Hill, J. K., Ohlemüller, R., Roy, D. B. \& Thomas, C. D. Rapid range shifts of species associated with high levels of climate warming. Science 333, 1024-1026 (2011).

3. Poloczanska, E. S. et al. Global imprint of climate change on marine life. Nat. Clim. Change 3, 919-925 (2013).

4. Lenoir, J. \& Svenning, J.-C. Climate-related range shifts - a global multidimensional synthesis and new research directions. Ecography 38, 15-28 (2015).

5. Pecl, G. T. et al. Biodiversity redistribution under climate change: Impacts on ecosystems and human well-being. Science 355, eaai9214 (2017).

6. Loarie, S. R. et al. The velocity of climate change. Nature 462, 1052-1055 (2009).

7. Burrows, M. T. et al. The pace of shifting climate in marine and terrestrial ecosystems. Science 334, 652-655 (2011).

8. Pinsky, M. L., Worm, B., Fogarty, M. J., Sarmiento, J. L. \& Levin, S. A. Marine taxa track local climate velocities. Science 341, 1239-1242 (2013).

9. Bertrand, R. et al. Changes in plant community composition lag behind climate warming in lowland forests. Nature 479, 517-520 (2011).

10. Devictor, V. et al. Differences in the climatic debts of birds and butterflies at a continental scale. Nat. Clim. Change 2, 121-124 (2012).

11. Pinsky, M. L., Eikeset, A. M., McCauley, D. J., Payne, J. L. \& Sunday, J. M. Greater vulnerability to warming of marine versus terrestrial ectotherms. Nature 569, 108 (2019).

12. Pinsky, M. L., Selden, R. L. \& Kitchel, Z. J. Climate-driven shifts in marine species ranges: scaling from organisms to communities. Annu. Rev. Mar. Sci. 12, 153-179 (2020). 
13. Comte, L. et al. BioShifts: a global geo-database of climate-induced species redistribution over land and sea. Figshare Digit. Repos. (2020) doi:10.6084/m9.figshare.7413365.

14. Brown, C. J. et al. Ecological and methodological drivers of species' distribution and phenology responses to climate change. Glob. Change Biol. 22, 1548-1560 (2016).

15. Feeley, K. J., Stroud, J. T. \& Perez, T. M. Most 'global' reviews of species' responses to climate change are not truly global. Divers. Distrib. 23, 231-234 (2017).

16. Friedman, A. R., Hwang, Y.-T., Chiang, J. C. H. \& Frierson, D. M. W. Interhemispheric Temperature Asymmetry over the Twentieth Century and in Future Projections. J. Clim. 26, 5419-5433 (2013).

17. Rumpf, S. B., Hülber, K., Zimmermann, N. E. \& Dullinger, S. Elevational rear edges shifted at least as much as leading edges over the last century. Glob. Ecol. Biogeogr. 28, 533-543 (2019).

18. Freeman, B. G., Lee Yaw, J. A., Sunday, J. M. \& Hargreaves, A. L. Expanding, shifting and shrinking: The impact of global warming on species' elevational distributions. Glob. Ecol. Biogeogr. 27, 1268-1276 (2018).

19. Halpern, B. S. et al. A Global Map of Human Impact on Marine Ecosystems. Science 319, 948-952 (2008).

20. Venter, O. et al. Global terrestrial human footprint maps for 1993 and 2009. Sci. Data 3, 160067 (2016).

21. Paaijmans, K. P. et al. Temperature variation makes ectotherms more sensitive to climate change. Glob. Change Biol. 19, 2373-2380 (2013).

22. Sunday, J. M., Bates, A. E. \& Dulvy, N. K. Thermal tolerance and the global redistribution of animals. Nat. Clim. Change 2, 686-690 (2012). 
23. Angert, A. L. et al. Do species' traits predict recent shifts at expanding range edges? Ecol. Lett. 14, 677-689 (2011).

24. Guo, F., Lenoir, J. \& Bonebrake, T. C. Land-use change interacts with climate to determine elevational species redistribution. Nat. Commun. 9, 1315 (2018).

25. Bertrand, R. et al. Ecological constraints increase the climatic debt in forests. Nat. Commun. $7,12643(2016)$

26. Warren, M. S. et al. Rapid responses of British butterflies to opposing forces of climate and habitat change. Nature 414, 65 (2001).

27. Engelhard, G. H., Righton, D. A. \& Pinnegar, J. K. Climate change and fishing: a century of shifting distribution in North Sea cod. Glob. Change Biol. 20, 2473-2483 (2014).

28. Troudet, J., Grandcolas, P., Blin, A., Vignes-Lebbe, R. \& Legendre, F. Taxonomic bias in biodiversity data and societal preferences. Sci. Rep. 7, 1-14 (2017).

29. Kjesbu, O. S. et al. Synergies between climate and management for Atlantic cod fisheries at high latitudes. Proc. Natl. Acad. Sci. 111, 3478-3483 (2014).

30. Schloss, C. A., Nuñez, T. A. \& Lawler, J. J. Dispersal will limit ability of mammals to track climate change in the Western Hemisphere. Proc. Natl. Acad. Sci. 109, 8606-8611 (2012).

31. Pounds, J. A. et al. Widespread amphibian extinctions from epidemic disease driven by global warming. Nature 439, 161-167 (2006).

32. Schemske, D. W., Mittelbach, G. G., Cornell, H. V., Sobel, J. M. \& Roy, K. Is there a latitudinal gradient in the importance of biotic interactions? Annu. Rev. Ecol. Evol. Syst. 40, 245-269 (2009).

33. HilleRisLambers, J., Harsch, M. A., Ettinger, A. K., Ford, K. R. \& Theobald, E. J. How will biotic interactions influence climate change-induced range shifts? Ann. N. Y. Acad. Sci. 1297, 112-125 (2013). 
34. Lenoir, J. et al. Local temperatures inferred from plant communities suggest strong spatial buffering of climate warming across Northern Europe. Glob. Change Biol. 19, 1470-1481 (2013).

35. Graae, B. J. et al. Stay or go - how topographic complexity influences alpine plant population and community responses to climate change. Perspect. Plant Ecol. Evol. Syst. 30, $41-50$ (2018).

36. Vergés, A. et al. The tropicalization of temperate marine ecosystems: climate-mediated changes in herbivory and community phase shifts. Proc. R. Soc. B Biol. Sci. 281, (2014).

37. Vergés, A. et al. Tropicalisation of temperate reefs: Implications for ecosystem functions and management actions. Funct. Ecol. 33, 1000-1013 (2019).

38. Vergés, A. et al. Long-term empirical evidence of ocean warming leading to tropicalization of fish communities, increased herbivory, and loss of kelp. Proc. Natl. Acad. Sci. 113, 13791-13796 (2016).

39. Kattge, J. et al. TRY - a global database of plant traits. Glob. Change Biol. 17, 2905-2935 (2011).

40. Kissling, W. D. et al. Establishing macroecological trait datasets: digitalization, extrapolation, and validation of diet preferences in terrestrial mammals worldwide. Ecol. Evol. 4, 2913-2930 (2014).

41. Meiri, S. Traits of lizards of the world: Variation around a successful evolutionary design. Glob. Ecol. Biogeogr. 27, 1168-1172 (2018).

42. Oliveira, B. F., São-Pedro, V. A., Santos-Barrera, G., Penone, C. \& Costa, G. C. AmphiBIO, a global database for amphibian ecological traits. Sci. Data 4, 1-7 (2017).

43. Frimpong, E. A. \& Angermeier, P. L. Fish Traits: A Database of Ecological and Life-history Traits of Freshwater Fishes of the United States. Fisheries 34, 487-495 (2009). 
44. Wilman, H. et al. EltonTraits 1.0: Species-level foraging attributes of the world's birds and mammals. Ecology 95, 2027-2027 (2014).

45. Agnihotri, P. et al. Climate change-driven shifts in elevation and ecophysiological traits of Himalayan plants during the past century. Curr. Sci. 112, 595 (2017).

46. Aguirre-Gutiérrez, J., Kissling, W. D. \& Carvalheiro, L. G. Functional traits help to explain half-century long shifts in pollinator distributions. Sci. Rep. 6, 24451 (2016).

47. Akatov, P. V. Changes in the upper limits of tree species distribution in the Western Caucasus (Belaya River basin) related to recent climate warming. Russ. J. Ecol. 40, 33-38 (2009).

48. Alofs, K. M., Jackson, D. A. \& Lester, N. P. Ontario freshwater fishes demonstrate differing range-boundary shifts in a warming climate. Divers. Distrib. 20, 123-136 (2014).

49. Amano, T. et al. Links between plant species' spatial and temporal responses to a warming climate. Proc. R. Soc. Lond. B Biol. Sci. 281, 20133017 (2014).

50. Ambrosini, R. et al. Climate change and the long-term northward shift in the African wintering range of the barn swallow Hirundo rustica. Clim. Res. 49, 131-141 (2011).

51. Angelo, C. L. \& Daehler, C. C. Upward expansion of fire-adapted grasses along a warming tropical elevation gradient. Ecography 36, 551-559 (2013).

52. Archaux, F. Breeding upwards when climate is becoming warmer: no bird response in the French Alps. Ibis 146, 138-144 (2004).

53. Ash, J. D., Givnish, T. J. \& Waller, D. M. Tracking lags in historical plant species' shifts in relation to regional climate change. Glob. Change Biol. 23, 1305-1315 (2017).

54. Asher, J., Fox, R. \& Warren, M. S. British butterfly distributions and the 2010 target. J. Insect Conserv. 15, 291-299 (2011). 
55. Assandri, G. \& Morganti, M. Is the spectacled warbler Sylvia conspicillata expanding northward because of climate warming? Bird Study 62, 126-131 (2015).

56. Auer, S. K. \& King, D. I. Ecological and life-history traits explain recent boundary shifts in elevation and latitude of western North American songbirds. Glob. Ecol. Biogeogr. 23, 867875 (2014).

57. Bässler, C., Hothorn, T., Brandl, R. \& Müller, J. Insects overshoot the expected upslope shift caused by climate warming. PLOS ONE 8, e65842 (2013).

58. Batdorf, K. E. Distributional changes in Ohio's breeding birds and the importance of climate and land cover change. (The Ohio State University, 2012).

59. Battisti, A. et al. Expansion of geographic range in the pine processionary moth caused by increased winter temperatures. Ecol. Appl. 15, 2084-2096 (2005).

60. Baur, B. \& Baur, A. Snails keep the pace: shift in upper elevation limit on mountain slopes as a response to climate warming. Can. J. Zool. 91, 596-599 (2013).

61. Beaugrand, G., Luczak, C. \& Edwards, M. Rapid biogeographical plankton shifts in the North Atlantic Ocean. Glob. Change Biol. 15, 1790-1803 (2009).

62. Bebber, D. P., Ramotowski, M. A. T. \& Gurr, S. J. Crop pests and pathogens move polewards in a warming world. Nat. Clim. Change 3, 985-988 (2013).

63. Beever, E. A., Ray, C., Wilkening, J. L., Brussard, P. F. \& Mote, P. W. Contemporary climate change alters the pace and drivers of extinction. Glob. Change Biol. 17, 2054-2070 (2011).

64. Bergamini, A., Ungricht, S. \& Hofmann, H. An elevational shift of cryophilous bryophytes in the last century - an effect of climate warming? Divers. Distrib. 15, 871-879 (2009). 
65. Berke, S. K. et al. Range shifts and species diversity in marine ecosystem engineers: patterns and predictions for European sedimentary habitats. Glob. Ecol. Biogeogr. 19, 223-232 (2010).

66. Betzholtz, P., Pettersson, L. B., Ryrholm, N. \& Franzen, M. With that diet, you will go far: trait-based analysis reveals a link between rapid range expansion and a nitrogen-favoured diet. Proc. R. Soc. B Biol. Sci. 280, 20122305 (2012).

67. Bhatta, K. P., Grytnes, J.-A. \& Vetaas, O. R. Downhill shift of alpine plant assemblages under contemporary climate and land-use changes. Ecosphere 9, e02084 (2018).

68. Biella, P. et al. Distribution patterns of the cold adapted bumblebee Bombus alpinus in the Alps and hints of an uphill shift (Insecta: Hymenoptera: Apidae). J. Insect Conserv. 21, 357366 (2017).

69. Bodin, J. et al. Shifts of forest species along an elevational gradient in Southeast France: climate change or stand maturation? J. Veg. Sci. 24, 269-283 (2013).

70. Boisvert-Marsh, L., Périé, C. \& de Blois, S. Shifting with climate? Evidence for recent changes in tree species distribution at high latitudes. Ecosphere 5, art83 (2014).

71. Botts, E. A., Erasmus, B. F. N. \& Alexander, G. J. Observed range dynamics of South African amphibians under conditions of global change. Austral Ecol. 40, 309-317 (2015).

72. Botts, E. A. Distribution change in South African frogs. (University of the Witwatersrand, 2012).

73. Bowman, J., Holloway, G. L., Malcolm, J. R., Middel, K. R. \& Wilson, P. J. Northern range boundary dynamics of southern flying squirrels: evidence of an energetic bottleneck. Can. J. Zool. 83, 1486-1494 (2005).

74. Brommer, J. E. The range margins of northern birds shift polewards. Ann. Zool. Fenn. 41, 391-397 (2004). 
75. Brommer, J. E., Lehikoinen, A. \& Valkama, J. The breeding ranges of central European and Arctic bird species move poleward. PLoS ONE 7, e43648 (2012).

76. Brusca, R. C. et al. Dramatic response to climate change in the Southwest: Robert Whittaker's 1963 Arizona Mountain plant transect revisited. Ecol. Evol. 3, 3636 (2013).

77. Bulgarella, M., Trewick, S. A., Minards, N. A., Jacobson, M. J. \& Morgan-Richards, M. Shifting ranges of two tree weta species (Hemideina spp.): competitive exclusion and changing climate. J. Biogeogr. 41, 524-535 (2014).

78. Büntgen, U. et al. Elevational range shifts in four mountain ungulate species from the Swiss Alps. Ecosphere 8, e01761 (2017).

79. Campos-Cerqueira, M. \& Aide, T. M. Lowland extirpation of anuran populations on a tropical mountain. PeerJ 5, e4059 (2017).

80. Campos-Cerqueira, M., Arendt, W. J., Wunderle, J. M. \& Aide, T. M. Have bird distributions shifted along an elevational gradient on a tropical mountain? Ecol. Evol. 7, 9914-9924 (2017).

81. Cannone, N. \& Pignatti, S. Ecological responses of plant species and communities to climate warming: upward shift or range filling processes? Clim. Change 123, 201-214 (2014).

82. Chen, I.-C. et al. Asymmetric boundary shifts of tropical montane Lepidoptera over four decades of climate warming. Glob. Ecol. Biogeogr. 20, 34-45 (2011).

83. Chen, I. et al. Elevation increases in moth assemblages over 42 years on a tropical mountain. Proc. Natl. Acad. Sci. USA 106, 1479-1483 (2009).

84. Chivers, W. J., Walne, A. W. \& Hays, G. C. Mismatch between marine plankton range movements and the velocity of climate change. Nat. Commun. 8, 14434 (2017).

85. Chust, G. et al. Are Calanus spp. shifting poleward in the North Atlantic? A habitat modelling approach. ICES J. Mar. Sci. 71, 241-253 (2014). 
86. Coals, P., Shmida, A., Vasl, A., Duguny, N. M. \& Gilbert, F. Elevation patterns of plant diversity and recent altitudinal range shifts in Sinai’s high-mountain flora. J. Veg. Sci. 29, 255-264 (2018).

87. Comte, L. \& Grenouillet, G. Do stream fish track climate change? Assessing distribution shifts in recent decades. Ecography 36, 1236-1246 (2013).

88. Coristine, L. E. \& Kerr, J. T. Temperature-related geographical shifts among passerines: contrasting processes along poleward and equatorward range margins. Ecol. Evol. 5, 5162$5176(2015)$

89. Courtin, F. et al. Updating the northern tsetse limit in Burkina Faso (1949-2009): impact of global change. Int. J. Environ. Res. Public. Health 7, 1708-1719 (2010).

90. Crimmins, S. M., Dobrowski, S. Z., Greenberg, J. A., Abatzoglou, J. T. \& Mynsberge, A. R. Changes in Climatic Water Balance Drive Downhill Shifts in Plant Species' Optimum Elevations. Science 331, 324-327 (2011).

91. Crozier, L. Winter warming facilitates range expansion: cold tolerance of the butterfly Atalopedes campestris. Oecologia 135, 648-656 (2003).

92. Cubillos, J. et al. Calcification morphotypes of the coccolithophorid Emiliania huxleyi in the Southern Ocean: changes in 2001 to 2006 compared to historical data. Mar. Ecol. Prog. Ser. 348, 47-54 (2007).

93. Currie, D. J. \& Venne, S. Climate change is not a major driver of shifts in the geographical distributions of North American birds. Glob. Ecol. Biogeogr. 26, 333-346 (2017).

94. Czortek, P. et al. Climate change, tourism and historical grazing influence the distribution of Carex lachenalii Schkuhr - A rare arctic-alpine species in the Tatra Mts. Sci. Total Environ. 618, 1628-1637 (2018). 
95. Dainese, M. et al. Human disturbance and upward expansion of plants in a warming climate. Nat. Clim. Change 7, 577-580 (2017).

96. Danby, R. K. \& Hik, D. S. Evidence of recent treeline dynamics in southwest Yukon from aerial photographs. ARTIC 60, 411-420 (2007).

97. Dawson, M. N., Grosberg, R. K., Stuart, Y. E. \& Sanford, E. Population genetic analysis of a recent range expansion: mechanisms regulating the poleward range limit in the volcano barnacle Tetraclita rubescens. Mol. Ecol. 19, 1585-1605 (2010).

98. Delava, E., Allemand, R., Léger, L., Fleury, F. \& Gibert, P. The rapid northward shift of the range margin of a Mediterranean parasitoid insect (Hymenoptera) associated with regional climate warming. J. Biogeogr. 41, 1379-1389 (2014).

99. DeLuca, W. V. Ecology and conservation of the montane forest avian community in northeastern North America. (University of Massachusetts, 2013).

100. DeLuca, W. V. \& King, D. I. Montane birds shift downslope despite recent warming in the northern Appalachian Mountains. J. Ornithol. 158, 493-505 (2017).

101. Dieker, P., Drees, C. \& Assmann, T. Two high-mountain burnet moth species (Lepidoptera, Zygaenidae) react differently to the global change drivers climate and landuse. Biol. Conserv. 144, 2810-2818 (2011).

102. Dobbertin, M. et al. The upward shift in altitude of pine mistletoe (Viscum album ssp. austriacum) in Switzerland - the result of climate warming? Int. J. Biometeorol. 50, 40-47 (2005).

103. Dolezal, J. et al. Vegetation dynamics at the upper elevational limit of vascular plants in Himalaya. Sci. Rep. 6, 24881 (2016). 
902

903

904

905

906

907

908

909

910

911

912

913

914

915

916

917

918

919

920

921

922

923

104. Dou, H., Jiang, G., Stott, P. \& Piao, R. Climate change impacts population dynamics and distribution shift of moose (Alces alces) in Heilongjiang Province of China. Ecol. Res. 28, 625-632 (2013).

105. Duarte, L. et al. Recent and historical range shifts of two canopy-forming seaweeds in north Spain and the link with trends in sea surface temperature. Acta Oecologica 51, 1-10 (2013).

106. Dulvy, N. K. et al. Climate change and deepening of the North Sea fish assemblage: a biotic indicator of warming seas. J. Appl. Ecol. 45, 1029-1039 (2008).

107. Dumais, C., Ropars, P., Denis, M., Dufour-Tremblay, G. \& Boudreau, S. Are low altitude alpine tundra ecosystems under threat? A case study from the Parc National de la Gaspésie, Québec. Environ. Res. Lett. 9, 094001 (2014).

108. Engelhard, G. H., Pinnegar, J. K., Kell, L. T. \& Rijnsdorp, A. D. Nine decades of North Sea sole and plaice distribution. ICES J. Mar. Sci. 68, 1090-1104 (2011).

109. Eskildsen, A. et al. Testing species distribution models across space and time: high latitude butterflies and recent warming. Glob. Ecol. Biogeogr. 22, 1293-1303 (2013).

110. Feeley, K. J. et al. Upslope migration of Andean trees. J. Biogeogr. 38, 783-791 (2011).

111. Fei, S. et al. Divergence of species responses to climate change. Sci. Adv. 3, e1603055 (2017).

112. Felde, V. A., Kapfer, J. \& Grytnes, J. Upward shift in elevational plant species ranges in Sikkilsdalen, central Norway. Ecography 35, 922-932 (2012).

113. Fenberg, P. B. \& Rivadeneira, M. M. Range limits and geographic patterns of abundance of the rocky intertidal owl limpet, Lottia gigantea. J. Biogeogr. 38, 2286-2298 (2011). 
924 114. Flousek, J., Telenský, T., Hanzelka, J. \& Reif, J. Population trends of central European 925 montane birds provide evidence for adverse impacts of climate change on high-altitude species. PLoS ONE 10, e0139465 (2015).

927 115. Forero-Medina, G., Terborgh, J., Socolar, S. J. \& Pimm, S. L. Elevational ranges of birds

on a tropical montane gradient lag behind warming temperatures. PLOS ONE 6, e28535 (2011).

116. Forsman, A., Betzholtz, P. \& Franzén, M. Faster poleward range shifts in moths with more variable colour patterns. Sci. Rep. 6, 36265 (2016).

117. Fox, R. et al. Moths count: recording moths for conservation in the UK. J. Insect Conserv. 15, 55-68 (2011).

118. Franco, A. M. A. et al. Impacts of climate warming and habitat loss on extinctions at species’ low-latitude range boundaries. Glob. Change Biol. 12, 1545-1553 (2006).

119. Freeman, B. G. \& Freeman, A. M. C. Rapid upslope shifts in New Guinean birds illustrate strong distributional responses of tropical montane species to global warming. Proc. Natl. Acad. Sci. 111, 4490-4494 (2014).

120. Frei, E., Bodin, J. \& Walther, G.-R. Plant species' range shifts in mountainous areas - all uphill from here? Bot. Helvetica 120, 117-128 (2010).

121. Gamache, I. \& Payette, S. Latitudinal response of subarctic tree lines to recent climate change in eastern Canada. J. Biogeogr. 32, 849-862 (2005).

122. Gonzalez, P. Desertification and a shift of forest species in the West African Sahel. Clim. Res. 17, 217-228 (2001).

123. Greenlee, E. S. The effects of a warming climate on the migratory strategies of a putatively non- migratory bird, the gray jay (Perisoreus canadensis). (The Ohio State University, 2012). 
948 124. Greenwood, S., Chen, J.-C., Chen, C.-T. \& Jump, A. S. Strong topographic sheltering 949 effects lead to spatially complex treeline advance and increased forest density in a $950 \quad$ subtropical mountain region. Glob. Change Biol. 20, 3756-3766 (2014).

951 125. Grewe, Y., Hof, C., Dehling, D. M., Brandl, R. \& Brändle, M. Recent range shifts of 952 953 954 European dragonflies provide support for an inverse relationship between habitat predictability and dispersal. Glob. Ecol. Biogeogr. 22, 403-409 (2013).

126. Groom, Q. J. Some poleward movement of British native vascular plants is occurring, but the fingerprint of climate change is not evident. PeerJ 1, e77 (2013).

127. Hale, S. S., Buffum, H. W., Kiddon, J. A. \& Hughes, M. M. Subtidal benthic invertebrates shifting northward along the US Atlantic Coast. Estuaries Coasts 40, 17441756 (2017).

128. Hargrove, L. J. Limits to species' distributions: spatial structure and dynamics of breeding bird populations along an ecological gradient. (University of California Riverside, 2010).

129. Harris, J. B. C. et al. Using diverse data sources to detect elevational range changes of birds on Mount Kinabalu, Malaysian Borneo. Raffles Bull. Zool. Supl 25, 197-247 (2012).

130. Hassall, C. Odonata as candidate macroecological barometers for global climate change. Freshw. Sci. 34, 1040-1049 (2015).

131. Hermes, C., Jansen, J. \& Schaefer, H. M. Habitat requirements and population estimate of the endangered Ecuadorian Tapaculo Scytalopus robbinsi. Bird Conserv. Int. 28, 302-318 (2018).

132. Hernández, L., Cañellas, I., Alberdi, I., Torres, I. \& Montes, F. Assessing changes in species distribution from sequential large-scale forest inventories. Ann. For. Sci. 71, 161-171 (2014). 
972 133. Hernández, L., Sánchez de Dios, R., Montes, F., Sainz-Ollero, H. \& Cañellas, I. 973 Exploring range shifts of contrasting tree species across a bioclimatic transition zone. Eur. J. 974 For. Res. 136, 481-492 (2017).

975 134. Hersteinsson, P. \& Macdonald, D. W. Interspecific competition and the geographical 976 distribution of red and artic foxes Vulpes vulpes and Alopex lagopus. OIKOS 64, 505-515 977

135. Hickling, R., Roy, D. B., Hill, J. K. \& Thomas, C. D. A northward shift of range margins in British Odonata. Glob. Change Biol. 11, 502-506 (2005).

136. Hiddink, J. G., Burrows, M. T. \& García Molinos, J. Temperature tracking by North Sea benthic invertebrates in response to climate change. Glob. Change Biol. 21, 117-129 (2015).

137. Hill, N. J., Tobin, A. J., Reside, A. E., Pepperell, J. G. \& Bridge, T. C. L. Dynamic habitat suitability modelling reveals rapid poleward distribution shift in a mobile apex predator. Glob. Change Biol. 22, 1086-1096 (2016).

138. Hitch, A. T. \& Leberg, P. L. Breeding distributions of North American bird species moving north as a result of climate change. Conserv. Biol. 21, 534-539 (2007).

139. Hofgaard, A., Tømmervik, H., Rees, G. \& Hanssen, F. Latitudinal forest advance in northernmost Norway since the early 20th century. J. Biogeogr. 40, 938-949 (2013).

140. Holzinger, B., Hülber, K., Camenisch, M. \& Grabherr, G. Changes in plant species richness over the last century in the eastern Swiss Alps: elevational gradient, bedrock effects and migration rates. Plant Ecol. 195, 179-196 (2008).

141. Hovick, T. J. et al. Informing conservation by identifying range shift patterns across breeding habitats and migration strategies. Biodivers. Conserv. 25, 345-356 (2016). 
142. Hsieh, C.-H., Kim, H. J., Watson, W., Di Lorenzo, E. \& Sugihara, G. Climate-driven changes in abundance and distribution of larvae of oceanic fishes in the southern California region. Glob. Change Biol. 15, 2137-2152 (2009).

143. Hsieh, C., Reiss, C. S., Hewitt, R. P. \& Sugihara, G. Spatial analysis shows that fishing enhances the climatic sensitivity of marine fishes. Can. J. Fish. Aquat. Sci. 65, 947-961 (2008).

144. Huang, Q., Sauer, J. R. \& Dubayah, R. O. Multidirectional abundance shifts among North American birds and the relative influence of multifaceted climate factors. Glob. Change Biol. 23, 3610-3622 (2017).

145. Jepsen, J. U., Hagen, S. B., Ims, R. A. \& Yoccoz, N. G. Climate change and outbreaks of the geometrids Operophtera brumata and Epirrita autumnata in subarctic birch forest: evidence of a recent outbreak range expansion. J. Anim. Ecol. 77, 257-264 (2008).

146. Jiménez-Alfaro, B., Gavilán, R. G., Escudero, A., Iriondo, J. M. \& Fernández-González, F. Decline of dry grassland specialists in Mediterranean high-mountain communities influenced by recent climate warming. J. Veg. Sci. 25, 1394-1404 (2014).

147. Jones, S. J., Lima, F. P. \& Wethey, D. S. Rising environmental temperatures and biogeography: poleward range contraction of the blue mussel, Mytilus edulis L., in the western Atlantic. J. Biogeogr. 37, 2243-2259 (2010).

148. Jones, S. J., Southward, A. J. \& Wethey, D. S. Climate change and historical biogeography of the barnacle Semibalanus balanoides. Glob. Ecol. Biogeogr. 21, 716-724 (2012).

149. Jore, S. et al. Multi-source analysis reveals latitudinal and altitudinal shifts in range of Ixodes ricinus at its northern distribution limit. Parasit. Vectors 4, 84 (2011). 
1017 150. Jump, A. S., Huang, T. \& Chou, C. Rapid altitudinal migration of mountain plants in 1018 Taiwan and its implications for high altitude biodiversity. Ecography 35, 204-210 (2012).

1019 151. Juvik, J., Rodomsky, B., Price, J., Hansen, E. \& Kueffer, C. 'The upper limits of 1020 vegetation on Mauna Loa, Hawaii’: a 50th-anniversary reassessment. Ecology 92, 518-525 $1021 \quad$ (2011).

1022 152. Kawakami, Y., Yamazaki, K. \& Ohashi, K. Northward expansion and climatic factors 1023 affecting the distribution limits of Cheilomenes sexmaculata (Coleoptera: Coccinellidae) in 1024 Japan. Appl. Entomol. Zool. 49, 59-66 (2014).

1025 153. Kelly, A. E. \& Goulden, M. L. Rapid shifts in plant distribution with recent climate 1026 change. Proc. Natl. Acad. Sci. USA 105, 11823-11826 (2008).

1027 154. Kerby, T. K., Cheung, W. W. L., van Oosterhout, C. \& Engelhard, G. H. Wondering 1028 about wandering whiting: distribution of North Sea whiting between the 1920s and 2000s. $1029 \quad$ Fish. Res. 145, 54-65 (2013).

1030 155. Kerr, J. T. et al. Climate change impacts on bumblebees converge across continents. $1031 \quad$ Science 349, 177-180 (2015).

1032 156. Kirchman, J. J. \& Van Keuren, A. E. Altitudinal range shifts of birds at the southern 1033 periphery of the boreal forest: 40 years of change in the Adirondack mountains. Wilson J. 1034 Ornithol. 129, 742-753 (2017).

1035 157. Kitahara, M., Iriki, M. \& Shimizu, G. On the relathionship between the northward 1036 distributional expansion of the great mormon butterfly, Papilio memnon Lineatus, and 1037 climatic warming in Japan. Trans. Lepidopterol. Soc. Jpn. 52, 253-264 (2001).

1038 158. Kleisner, K. M. et al. The effects of sub-regional climate velocity on the distribution and 1039 spatial extent of marine species assemblages. PLOS ONE 11, e0149220 (2016). 
1040 159. Koide, D., Yoshida, K., Daehler, C. C. \& Mueller-Dombois, D. An upward elevation 1041 shift of native and non-native vascular plants over 40 years on the island of Hawai'i. J. Veg. 1042 Sci. 28, 939-950 (2017).

1043 160. Kopp, C. W. \& Cleland, E. E. Shifts in plant species elevational range limits and 1044 abundances observed over nearly five decades in a western North America mountain range. 1045 J. Veg. Sci. 25, 135-146 (2014).

1046 161. Kotwicki, S. \& Lauth, R. R. Detecting temporal trends and environmentally-driven 1047 changes in the spatial distribution of bottom fishes and crabs on the eastern Bering Sea shelf. 1048 Deep Sea Res. Part II Top. Stud. Oceanogr. 94, 231-243 (2013).

1049

162. Kreuser, J. M. Climate change, range shifts, and differential guild responses of Michigan 1050 breeding birds. (Michigan State University, 2013).

1051

163. Kuhn, E., Lenoir, J., Piedallu, C. \& Gégout, J.-C. Early signs of range disjunction of 1052 submountainous plant species: an unexplored consequence of future and contemporary 1053 climate changes. Glob. Change Biol. 22, 2094-2105 (2016).

1054

164. Kuletz, K. J., Renner, M., Labunski, E. A. \& Hunt, G. L. Changes in the distribution and 1055 1056 1057 1058 1059 1060 abundance of albatrosses in the eastern Bering Sea: 1975-2010. Deep Sea Res. Part II Top. Stud. Oceanogr. 109, 282-292 (2014).

165. Kullman, L., Journal, T. \& Feb, N. Rapid recent range-margin rise of tree and shrub species in the Swedish Scandes. J. Ecol. 90, 68-77 (2002).

166. Kullman, L. \& Öberg, L. Post-Little Ice Age tree line rise and climate warming in the Swedish Scandes: a landscape ecological perspective. J. Ecol. 97, 415-429 (2009).

167. Kurihara, T. et al. Area-specific temporal changes of species composition and speciesspecific range shifts in rocky-shore mollusks associated with warming Kuroshio Current. Mar. Biol. 158, 2095-2107 (2011). 
1064 168. Kwon, T., Lee, C. M. \& Kim, S. Northward range shifts in Korean butterflies. Clim.

$1065 \quad$ Change 126, 163-174 (2014).

1066 169. La Sorte, F. A. \& Thompson III, F. R. Poleward shifts in winter ranges of North 1067 American birds. Ecology 88, 1803-1812 (2007).

1068 170. Landa, C. S., Ottersen, G., Sundby, S., Dingsør, G. E. \& Stiansen, J. E. Recruitment, 1069 distribution boundary and habitat temperature of an arcto-boreal gadoid in a climatically 1070 changing environment: a case study on Northeast Arctic haddock (Melanogrammus 1071 aeglefinus). Fish. Oceanogr. 23, 506-520 (2014).

1072 171. Larrucea, E. S. \& Brussard, P. F. Shift in location of pygmy rabbit (Brachylagus 1073 idahoensis) habitat in response to changing environments. J. Arid Environ. 72, 1636-1643 1074 (2008).

1075 172. Lättman, H., Milberg, P., Palmer, M. W. \& Mattsson, J. Changes in the distributions of 1076 epiphytic lichens in southern Sweden using a new statistical method. Nord. J. Bot. 27, 413$1077 \quad 418(2009)$.

1078 173. le Roux, P. C. \& McGeoch, M. A. Rapid range expansion and community reorganization 1079 in response to warming. Glob. Change Biol. 14, 2950-2962 (2008).

1080 174. Lehikoinen, A. \& Virkkala, R. North by north-west: climate change and directions of 1081 density shifts in birds. Glob. Change Biol. 22, 1121-1129 (2016).

1082 175. Leidenberger, S., Harding, K. \& Jonsson, P. R. Ecology and distribution of the isopod 1083 genus Idotea in the Baltic Sea: key species in a changing environment. J. Crustac. Biol. 32, $1084 \quad 359-381(2012)$.

1085 176. Lenoir, J., Gegout, J. C., Marquet, P. A., de Ruffray, P. \& Brisse, H. A significant 1086 upward shift in plant species optimum elevation during the 20th century. Science 320, 1768$1087 \quad 1771(2008)$. 
1088 177. Leonelli, G., Pelfini, M., Morra di Cella, U. \& Garavaglia, V. Climate warming and the recent treeline shift in the European Alps: the role of geomorphological factors in highaltitude sites. AMBIO 40, 264-273 (2011).

1091

1092

1093

1094

1095

1096

1097

1098

1099

1100

1101

1102

1103

1104

1105

1106

1107

1108

1109

1110

1111

178. Lima, F. P., Ribeiro, P. A., Queiroz, N., Hawkins, S. J. \& Santos, A. M. Do distributional shifts of northern and southern species of algae match the warming pattern? Glob. Change Biol. 13, 2592-2604 (2007).

179. Lindley, J. \& Daykin, S. Variations in the distributions of Centropages chierchiae and Temora stylifera (Copepoda: Calanoida) in the north-eastern Atlantic Ocean and western European shelf waters. ICES J. Mar. Sci. 62, 869-877 (2005).

180. Ling, S. D., Johnson, C. R., Ridgway, K., Hobday, A. J. \& Haddon, M. Climate-driven range extension of a sea urchin: inferring future trends by analysis of recent population dynamics. Glob. Change Biol. 15, 719-731 (2009).

181. MacLaren, C. A. Climate change drives decline of Juniperus seravschanica in Oman. $J$. Arid Environ. 128, 91-100 (2016).

182. MacLean, I. M. D. et al. Climate change causes rapid changes in the distribution and site abundance of birds in winter. Glob. Change Biol. 14, 2489-2500 (2008).

183. Mair, L. et al. Temporal variation in responses of species to four decades of climate warming. Glob. Change Biol. 18, 2439-2447 (2012).

184. Máliš, F. et al. Life stage, not climate change, explains observed tree range shifts. Glob. Change Biol. 22, 1904-1914 (2016).

185. Martinet, B. et al. Forward to the north: two Euro-Mediterranean bumblebee species now cross the Arctic Circle. Ann. Société Entomol. Fr. NS 51, 303-309 (2015).

186. Mason, S. C. et al. Geographical range margins of many taxonomic groups continue to shift polewards. Biol. J. Linn. Soc. 115, 586-597 (2015). 
1112 187. Massimino, D., Johnston, A. \& Pearce-Higgins, J. W. The geographical range of British 1113 birds expands during 15 years of warming. Bird Study 62, 523-534 (2015).

1114 188. Mathisen, I. E., Mikheeva, A., Tutubalina, O. V., Aune, S. \& Hofgaard, A. Fifty years of 1115 tree line change in the Khibiny Mountains, Russia: advantages of combined remote sensing 1116 and dendroecological approaches. Appl. Veg. Sci. 17, 6-16 (2014).

1117 189. Melles, S. J., Fortin, M. J., Lindsay, K. \& Badzinski, D. Expanding northward: influence 1118 of climate change, forest connectivity, and population processes on a threatened species' 1119 range shift. Glob. Change Biol. 17, 17-31 (2011).

1120 190. Menéndez, R., González-Megías, A., Jay-Robert, P. \& Marquéz-Ferrando, R. Climate 1121 change and elevational range shifts: evidence from dung beetles in two European mountain 1122 ranges. Glob. Ecol. Biogeogr. 23, 646-657 (2014).

1123

1124

1125

1126

1127

1128

1129

1130

1131

1132

1133

1134

1135

191. Merrill, R. M. et al. Combined effects of climate and biotic interactions on the elevational range of a phytophagous insect. J. Anim. Ecol. 77, 145-155 (2008).

192. Mieszkowska, N. et al. Changes in the range of some common rocky shore species in Britain - A response to climate change? Hydrobiologia 555, 241-251 (2006).

193. Molina-Martínez, A. et al. Changes in butterfly distributions and species assemblages on a Neotropical mountain range in response to global warming and anthropogenic land use. Divers. Distrib. 22, 1085-1098 (2016).

194. Monahan, W. B. \& Hijmans, R. J. Ecophysiological constraints shape autumn migratory response to climate change in the North American field sparrow. Biol. Lett. 4, 595-598 (2008).

195. Morelli, T. L. et al. Anthropogenic refugia ameliorate the severe climate-related decline of a montane mammal along its trailing edge. Proc. R. Soc. Lond. B Biol. Sci. 279, 42794286 (2012). 
1136 196. Moreno-Fernández, D., Hernández, L., Sánchez-González, M., Cañellas, I. \& Montes, F.

1137 Space-time modeling of changes in the abundance and distribution of tree species. For. Ecol.

1138 Manag. 372, 206-216 (2016).

1139 197. Moreno-Rueda, G., Pleguezuelos, J. M., Pizarro, M. \& Montori, A. Northward shifts of 1140 the distributions of Spanish reptiles in association with climate change. Conserv. Biol. 26, $1141 \quad 278-283(2012)$.

1142 198. Moret, P., Aráuz, M. de los Á., Gobbi, M. \& Barragán, Á. Climate warming effects in the 1143 tropical Andes: first evidence for upslope shifts of Carabidae (Coleoptera) in Ecuador. Insect 1144 Conserv. Divers. 9, 342-350 (2016).

1145 199. Moritz, C. et al. Impact of a Century of Climate Change on Small-Mammal Communities 1146 in Yosemite National Park, USA. Science 322, 261-264 (2008).

1147 200. Morueta-Holme, N. et al. Strong upslope shifts in Chimborazo's vegetation over two 1148 centuries since Humboldt. Proc. Natl. Acad. Sci. 112, 12741-12745 (2015).

1149 201. Moskwik, M. Recent elevational range expansions in plethodontid salamanders 1150 (Amphibia: Plethodontidae) in the southern Appalachian Mountains. J. Biogeogr. 41, 1957$1151 \quad 1966$ (2014).

1152 202. Mueter, F. J. \& Litzow, M. A. Sea ice retreat alters the biogeography of the Bering Sea 1153 continental shelf. Ecol. Appl. 18, 309-320 (2008).

1154 203. Myers, P., Lundrigan, B. L., Hoffman, S. M. G., Haraminac, A. P. \& Seto, S. H. Climate1155 induced changes in the small mammal communities of the Northern Great Lakes Region. $1156 \quad$ Glob. Change Biol. 15, 1434-1454 (2009).

1157 204. Neukermans, G., Oziel, L. \& Babin, M. Increased intrusion of warming Atlantic water 1158 leads to rapid expansion of temperate phytoplankton in the Arctic. Glob. Change Biol. 24, $1159 \quad 2545-2553(2018)$. 
1160 205. Nicastro, K. R. et al. Shift happens: trailing edge contraction associated with recent 1161 warming trends threatens a distinct genetic lineage in the marine macroalga Fucus 1162 vesiculosus. BMC Biol. 11, 6 (2013).

1163 206. Nicolas, D. et al. Impact of global warming on European tidal estuaries: some evidence 1164 of northward migration of estuarine fish species. Reg. Environ. Change 11, 639-649 (2011).

1165 207. Niven, D. K., Butcher, G. S. \& Bancroft, G. T. Christmas bird counts and climate change: 1166 northward shifts in early winter abundance. Am. Birds 63, 10-15 (2010).

1167 208. Nye, J. A., Link, J. S., Hare, J. A. \& Overholtz, W. J. Changing spatial distribution of fish 1168 stocks in relation to climate and population size on the Northeast United States continental 1169 shelf. Mar. Ecol. Prog. Ser. 393, 111-129 (2009).

1170 209. Orensanz, J. L., Ernst, B., Armstrong, D. A., Stabeno, P. J. \& Livingston, P. Contraction 1171 of the geographical range of distribution of snow crab (Chionoecetes Opilio) in the Eastern 1172 Bering Sea: an environmental ratchet ? CalCOFI Rep. 45, 65-79 (2004).

1173 210. Ottosen, K. M., Steingrund, P., Magnussen, E. \& Payne, M. R. Distribution and timing of 1174 spawning Faroe Plateau cod in relation to warming spring temperatures. Fish. Res. 198, 14 $1175 \quad 23(2018)$.

1176 211. Overholtz, W. J., Hare, J. A. \& Keith, C. M. Impacts of interannual environmental 1177 forcing and climate change on the distribution of Atlantic mackerel on the U.S. northeast 1178 continental shelf. Mar. Coast. Fish. 3, 219-232 (2011).

1179 212. Pakeman, R. J. et al. Species composition of coastal dune vegetation in Scotland has 1180 proved resistant to climate change over a third of a century. Glob. Change Biol. 21, 3738$1181 \quad 3747(2015)$. 
1182 213. Paprocki, N., Heath, J. A. \& Novak, S. J. Regional distribution shifts help explain local 1183 changes in wintering raptor abundance: implications for interpreting population trends. PLoS 1184 ONE 9, e86814 (2014).

1185 214. Parolo, G. \& Rossi, G. Upward migration of vascular plants following a climate warming 1186 trend in the Alps. Basic Appl. Ecol. 9, 100-107 (2008).

1187 215. Pateman, R. M., Hill, J. K., Roy, D. B., Fox, R. \& Thomas, C. D. Temperature-dependent 1188 alterations in host use drive rapid range expansion in a butterfly. Science 336, 1028-1030 $1189 \quad$ (2012).

1190 216. Peñuelas, J. \& Boada, M. A global change-induced biome shift in the Montseny 1191 mountains (NE Spain). Glob. Change Biol. 9, 131-140 (2003).

1192 217. Perissinotto, R., Pringle, E. L. \& Giliomee, J. H. Southward expansion in beetle and 1193 butterfly ranges in South Africa. Afr. Entomol. 19, 61-69 (2011).

1194 218. Pitt, N. R., Poloczanska, E. S. \& Hobday, A. J. Climate-driven range changes in 1195 Tasmanian intertidal fauna. Mar. Freshw. Res. 61, 963-970 (2010).

1196 219. Pernollet, C. A., Korner-Nievergelt, F. \& Jenni, L. Regional changes in the elevational 1197 distribution of the Alpine Rock Ptarmigan Lagopus muta helvetica in Switzerland. Ibis 157, $1198 \quad 823-836(2015)$.

1199 220. Péron, C. et al. Interdecadal changes in at-sea distribution and abundance of subantarctic 1200 seabirds along a latitudinal gradient in the Southern Indian Ocean. Glob. Change Biol. 16, $1201 \quad 1895-1909$ (2010).

1202 221. Perry, A. L., Low, P. J., Ellis, J. R. \& Reynolds, J. D. Climate change and distribution $1203 \quad$ shifts in marine fishes. Science 308, 1912-1915 (2005).

1204 222. Peterson, T. A. Subtle recent distributional shifts in Great Plains bird species. Southwest. $1205 \quad$ Nat. 48, 289-292 (2003). 
1206

1207

1208

1209

1210

1211

1212

1213

1214

1215

1216

1217

1218

1219

1220

1221

1222

1223

1224

1225

1226

1227

1228

223. Ploquin, E. F., Herrera, J. M. \& Obeso, J. R. Bumblebee community homogenization after uphill shifts in montane areas of northern Spain. Oecologia 173, 1649-1660 (2013).

224. Poloczanska, E. S. et al. Little change in the distribution of rocky shore faunal communities on the Australian east coast after 50years of rapid warming. J. Exp. Mar. Biol. Ecol. 400, 145-154 (2011).

225. Popy, S., Bordignon, L. \& Prodon, R. A weak upward elevational shift in the distributions of breeding birds in the Italian Alps. J. Biogeogr. 37, 57-67 (2009).

226. Potvin, D. A., Välimäki, K. \& Lehikoinen, A. Differences in shifts of wintering and breeding ranges lead to changing migration distances in European birds. J. Avian Biol. 47, 619-628 (2016).

227. Pöyry, J., Luoto, M., Heikkinen, R. K., Kuussaari, M. \& Saarinen, K. Species traits explain recent range shifts of Finnish butterflies. Glob. Change Biol. 15, 732-743 (2009).

228. Precht, W. F. \& Aronson, R. B. Climate flickers and range shifts of reef corals. Front. Ecol. Evol. 2, 307-314 (2004).

229. Pyke, G. H., Thomson, J. D., Inouye, D. W. \& Miller, T. J. Effects of climate change on phenologies and distributions of bumble bees and the plants they visit. Ecosphere 7, e01267 (2016).

230. Quero, J. Changes in the Euro Atlantic fish species composition resulting from fishing and ocean warming. Ital. J. Zool. 65, 493-499 (1998).

231. Rannow, S. Do shifting forest limits in south-west Norway keep up with climate change? Scand. J. For. Res. 28, 574-580 (2013).

232. Rappole, J. H., Glasscosk, S., Goldberg, K., Song, D. \& Faridani, S. Range change among new world tropical and subtropical birds. Bonn. Zool. Monogr. 57, 151-167 (2011). 
1229

1230

1231

1232

1233

1234

1235

1236

1237

1238

1239

1240

1241

1242

1243

1244

1245

1246

1247

1248

1249

1250

1251

1252

233. Raxworthy, C. J. et al. Extinction vulnerability of tropical montane endemism from warming and upslope displacement: a preliminary appraisal for the highest massif in Madagascar. Glob. Change Biol. 14, 1703-1720 (2008).

234. Reid, S. B. \& Goodman, D. H. Pacific lamprey in coastal drainages of California: occupancy patterns and contraction of the southern range. Trans. Am. Fish. Soc. 145, 703$711(2016)$.

235. Reif, J. \& Flousek, J. The role of species' ecological traits in climatically driven altitudinal range shifts of central European birds. Oikos 121, 1053-1060 (2012).

236. Renner, M. et al. Modeled distribution and abundance of a pelagic seabird reveal trends in relation to fisheries. Mar. Ecol. Prog. Ser. 484, 259-277 (2013).

237. Riley, M. E., Johnston, C. A., Feller, I. C. \& Griffen, B. D. Range expansion of Aratus pisonii (mangrove tree crab) into novel vegetative habitats. Southeast. Nat. 13, N43-N48 (2014).

238. Rivadeneira, M. M. \& Ferna, M. Shifts in southern endpoints of distribution in rocky intertidal species along the south-eastern Pacific coast. J. Biogeogr. 32, 203-209 (2005).

239. Rowe, K. C. et al. Spatially heterogeneous impact of climate change on small mammals of montane California. Proc. R. Soc. Lond. B Biol. Sci. 282, 20141857 (2014).

240. Rowe, R. J., Finarelli, J. A. \& Rickart, E. A. Range dynamics of small mammals along an elevational gradient over an 80-year interval. Glob. Change Biol. 16, 2930-2943 (2010).

241. Rubal, M., Veiga, P., Cacabelos, E., Moreira, J. \& Sousa-Pinto, I. Increasing sea surface temperature and range shifts of intertidal gastropods along the Iberian Peninsula. J. Sea Res. 77, 1-10 (2013)

242. Rumpf, S. B. et al. Range dynamics of mountain plants decrease with elevation. Proc. Natl. Acad. Sci. USA 115, 1848-1853 (2018). 
1253 243. Sabatés, A., Martín, P., Lloret, J. \& Raya, V. Sea warming and fish distribution: the case 1254 of the small pelagic fish, Sardinella aurita, in the western Mediterranean. Glob. Change Biol. 1255 12, 2209-2219 (2006).

1256 244. Santos, M. J., Thorne, J. H. \& Moritz, C. Synchronicity in elevation range shifts among 1257

1258

1259

1260

1261

1262

1263

1264

1265

1266

1267

1268

1269

1270

1271

1272

1273

1274

1275

1276

small mammals and vegetation over the last century is stronger for omnivores. Ecography

38, 556-568 (2015).

245. Savage, J. \& Vellend, M. Elevational shifts, biotic homogenization and time lags in vegetation change during 40 years of climate warming. Ecography 38, 546-555 (2015).

246. Serrano, E. et al. Rapid northward spread of a Zooxanthellate coral enhanced by artificial structures and sea warming in the western Mediterranean. PLOS ONE 8, e52739 (2013).

247. Sheldon, A. L. Possible climate-induced shift of stoneflies in a southern Appalachian catchment. Freshw. Sci. 31, 765-774 (2012).

248. Shiyatov, S. G., Terent'ev, M. M., Fomin, V. V. \& Zimmermann, N. E. Altitudinal and horizontal shifts of the upper boundaries of open and closed forests in the Polar Urals in the 20th century. Russ. J. Ecol. 38, 223-227 (2007).

249. Sittaro, F., Paquette, A., Messier, C. \& Nock, C. A. Tree range expansion in eastern North America fails to keep pace with climate warming at northern range limits. Glob. Change Biol. 23, 3292-3301 (2017).

250. Solow, A. et al. A test for a shift in the boundary of the geographical range of a species. Biol. Lett. 10, 20130808 (2014).

251. Song, X. et al. Climate warming-induced upward shift of Moso bamboo population on Tianmu Mountain, China. J. Mt. Sci. 10, 363-369 (2013).

252. Speed, J. D. M., Austrheim, G., Hester, A. J. \& Mysterud, A. Elevational advance of alpine plant communities is buffered by herbivory. J. Veg. Sci. 23, 617-625 (2012). 
1277 253. Stafford, R., Hart, A. G. \& Goodenough, A. E. A visual method to identify significant 1278 latitudinal changes in species’' distributions. Ecol. Inform. 15, 74-84 (2013).

1279 254. Stuart-Smith, R. D., Barrett, N. S., Stevenson, D. G. \& Edgar, G. J. Stability in temperate 1280 reef communities over a decadal time scale despite concurrent ocean warming. Glob. Change 1281 Biol. 16, 122-134 (2010).

1282 255. Stueve, K. M., Isaacs, R. E., Tyrrell, L. E. \& Densmore, R. V. Spatial variability of biotic 1283 and abiotic tree establishment constraints across a treeline ecotone in the Alaska Range. 1284 Ecology 92, 496-506 (2011).

1285 256. Sultaire, S. M. et al. Climate change surpasses land-use change in the contracting range 1286 boundary of a winter-adapted mammal. Proc. R. Soc. Lond. B Biol. Sci. 283, 20153104 1287 (2016).

1288 257. Swaby, S. E. \& Potts, G. W. The sailfin dory, a first British record. J. Fish Biol. 54, $1289 \quad 1338-1340(1999)$.

1290 258. Tape, K. D., Gustine, D. D., Ruess, R. W., Adams, L. G. \& Clark, J. A. Range expansion 1291 of moose in arctic Alaska linked to warming and increased shrub habitat. PLOS ONE 11, 1292 e0152636 (2016)

1293

259. Tayleur, C. et al. Swedish birds are tracking temperature but not rainfall: evidence from a 1294 decade of abundance changes. Glob. Ecol. Biogeogr. 24, 859-872 (2015).

1295 260. Telwala, Y., Brook, B. W., Manish, K. \& Pandit, M. K. Climate-induced elevational 1296 range shifts and increase in plant species richness in a Himalayan biodiversity epicentre. 1297 PLOS ONE 8, e57103 (2013).

1298 261. Thorson, J. T., Ianelli, J. N. \& Kotwicki, S. The relative influence of temperature and 1299 size-structure on fish distribution shifts: a case-study on walleye pollock in the Bering Sea. $1300 \quad$ Fish Fish. 18, 1073-1084 (2017). 
262. Tingley, M. W., Koo, M. S., Moritz, C., Rush, A. C. \& Beissinger, S. R. The push and pull of climate change causes heterogeneous shifts in avian elevational ranges. Glob. Change Biol. 18, 3279-3290 (2012).

263. Tougou, D., Musolin, D. L. \& Fujisaki, K. Some like it hot! Rapid climate change promotes changes in distribution ranges of Nezara viridula and Nezara antennata in Japan. Entomol. Exp. Appl. 130, 249-258 (2009).

264. Tryjanowski, P., Sparks, T. H. \& Profus, P. Uphill shifts in the distribution of the white stork Ciconia ciconia in southern Poland: the importance of nest quality. Divers. Distrib. 11, 219-223 (2005).

265. Tu, C., Tian, Y. \& Hsieh, C.-H. Effects of climate on temporal variation in the abundance and distribution of the demersal fish assemblage in the Tsushima Warm Current region of the Japan Sea. Fish. Oceanogr. 24, 177-189 (2015).

266. Urli, M. et al. Inferring shifts in tree species distribution using asymmetric distribution curves: a case study in the Iberian mountains. J. Veg. Sci. 25, 147-159 (2014).

267. Välimäki, K., Lindén, A. \& Lehikoinen, A. Velocity of density shifts in Finnish landbird species depends on their migration ecology and body mass. Oecologia 181, 313-321 (2016).

268. Van Bogaert, R. et al. A century of tree line changes in sub-Arctic Sweden shows local and regional variability and only a minor influence of 20 th century climate warming. $J$. Biogeogr. 38, 907-921 (2011).

269. van Hal, R., Smits, K. \& Rijnsdorp, A. D. How climate warming impacts the distribution and abundance of two small flatfish species in the North Sea. J. Sea Res. 64, 76-84 (2010).

270. VanDerWal, J. et al. Focus on poleward shifts in species' distribution underestimates the fingerprint of climate change. Nat. Clim. Change 3, 239-243 (2013). 
1324 271. Veech, J. A., Small, M. F. \& Baccus, J. T. The effect of habitat on the range expansion of 1325 a native and an introduced bird species. J. Biogeogr. 38, 69-77 (2011).

1326 272. Virkkala, R., Heikkinen, R. K., Lehikoinen, A. \& Valkama, J. Matching trends between 1327 recent distributional changes of northern-boreal birds and species-climate model predictions. Biol. Conserv. 172, 124-127 (2014).

273. Virkkala, R. \& Lehikoinen, A. Patterns of climate-induced density shifts of species: poleward shifts faster in northern boreal birds than in southern birds. Glob. Change Biol. 20, 2995-3003 (2014).

1332

274. Virkkala, R. \& Lehikoinen, A. Birds on the move in the face of climate change: high species turnover in northern Europe. Ecol. Evol. 7, 8201-8209 (2017).

275. Virtanen, R. et al. Recent vegetation changes at the high-latitude tree line ecotone are controlled by geomorphological disturbance, productivity and diversity. Glob. Ecol. Biogeogr. 19, 810-821 (2010).

276. Vittoz, P., Bodin, J., Ungricht, S., Burga, C. A. \& Walther, G. One century of vegetation change on Isla Persa, a nunatak in the Bernina massif in the Swiss Alps. J. Veg. Sci. 19, 671680 (2008).

277. Walters, G. E. \& Wilderbuer, T. K. Decreasing length at age in a rapidly expanding population of northern rock sole in the eastern Bering Sea and its effect on management advice. J. Sea Res. 44, 17-26 (2000).

278. Walther, G.-R., Beißner, S. \& Burga, C. A. Trends in the upward shift of alpine plants. J. Veg. Sci. 16, 541-548 (2005).

279. Wehtje, W. The range expansion of the great-tailed grackle (Quiscalus mexicanus Gmelin) in North America since 1880. J. Biogeogr. 30, 1593-1607 (2003). 
1347 280. Weinberg, J. Bathymetric shift in the distribution of Atlantic surfclams: response to 1348 warmer ocean temperature. ICES J. Mar. Sci. 62, 1444-1453 (2005).

1349 281. Wells, C. N. \& Tonkyn, D. W. Range collapse in the Diana fritillary, Speyeria diana 1350 (Nymphalidae). Insect Conserv. Divers. 7, 365-380 (2014).

1351 282. Wen, Z. et al. Heterogeneous distributional responses to climate warming: evidence from 1352 rodents along a subtropical elevational gradient. BMC Ecol. 17, 17 (2017).

1353 283. Wernberg, T. et al. Seaweed communities in retreat from ocean warming. Curr. Biol. 21, $1354 \quad 1828-1832(2011)$.

1355 284. Wethey, D. S. \& Woodin, S. A. Ecological hindcasting of biogeographic responses to 1356 climate change in the European intertidal zone. Hydrobiologia 606, 139-151 (2008).

1357 285. Wilson, R. J. et al. Changes to the elevational limits and extent of species ranges $1358 \quad$ associated with climate change. Ecol. Lett. 8, 1138-1146 (2005).

1359 286. Wilson, S., Anderson, E. M., Wilson, A. S. G., Bertram, D. F. \& Arcese, P. Citizen 1360 science reveals an extensive shift in the winter distribution of migratory western grebes. $1361 \quad$ PLOS ONE 8, e65408 (2013).

1362 287. Wolf, A., Zimmerman, N. B., Anderegg, W. R. L., Busby, P. E. \& Christensen, J. 1363 Altitudinal shifts of the native and introduced flora of California in the context of 20th1364 century warming. Glob. Ecol. Biogeogr. 25, 418-429 (2016).

1365 288. Wright, D. H., NGuyen, C. V. \& Anderson, S. Upward shifts in recruitment of high1366 elevation tree species in the northern Sierra Nevada, California. Calif. Fish Game 102, 17$1367 \quad 31(2016)$.

1368 289. Wu, J. Detecting and attributing the effects of climate change on the distributions of 1369 snake species over the past 50 years. Environ. Manage. 57, 207-219 (2016). 
1370 290. Wu, J. Can changes in the distribution of lizard species over the past 50 years be 1371 attributed to climate change? Theor. Appl. Climatol. 125, 785-798 (2016).

1372 291. Wu, J. \& Shi, Y. Attribution index for changes in migratory bird distributions: the role of 1373 climate change over the past 50 years in China. Ecol. Inform. 31, 147-155 (2016).

1374 292. Yamano, H., Sugihara, K. \& Nomura, K. Rapid poleward range expansion of tropical reef 1375 corals in response to rising sea surface temperatures. Geophys. Res. Lett. 38, 1-6 (2011).

1376 293. Yang, D.-S., Conroy, C. J. \& Moritz, C. Contrasting responses of Peromyscus mice of 1377 Yosemite National Park to recent climate change. Glob. Change Biol. 17, 2559-2566 (2011).

1378 294. Yang, L. et al. Long-term ecological data for conservation: range change in the black1379 billed capercaillie (Tetrao urogalloides) in northeast China (1970s-2070s). Ecol. Evol. 8, $1380 \quad 3862-3870(2018)$.

1381 295. Yemane, D. et al. Assessing changes in the distribution and range size of demersal fish 1382 populations in the Benguela Current Large Marine Ecosystem. Rev. Fish Biol. Fish. 24, 463$1383483(2014)$.

1384 296. Yukawa, J. et al. Distribution range shift of two allied species, Nezara viridula and N. 1385 antennata (Hemiptera: Pentatomidae), in Japan, possibly due to global warming. Appl. $1386 \quad$ Entomol. Zool. 42, 205-215 (2007).

1387 297. Zhang, R. et al. Geographic characteristics of sable (Martes zibellina) distribution over 1388 time in Northeast China. Ecol. Evol. 7, 4016-4023 (2017).

1389 298. Zhang, Y., Xu, M., Adams, J. \& Wang, X. Can Landsat imagery detect tree line 1390 dynamics? Int. J. Remote Sens. 30, 1327-1340 (2009).

1391 299. Zhu, K., Woodall, C. W. \& Clark, J. S. Failure to migrate: lack of tree range expansion in 1392 response to climate change. Glob. Change Biol. 18, 1042-1052 (2012). 
1393 300. Zuckerberg, B., Woods, A. M. \& Porter, W. F. Poleward shifts in breeding bird 1394 distributions in New York State. Glob. Change Biol. 15, 1866-1883 (2009).

1395 301. R Core Team. R: A Language and Environment for Statistical Computing. (2019).

1396 302. Chamberlain, S. A. \& Szöcs, E. taxize: taxonomic search and retrieval in R. 1397 F1000Research (2013) doi:10.12688/f1000research.2-191.v1.

1398 303. Gastner, M. T. \& Newman, M. E. J. Diffusion-based method for producing density1399 equalizing maps. Proc. Natl. Acad. Sci. 101, 7499-7504 (2004).

1400 304. Zuur, A. F., Ieno, E. N. \& Elphick, C. S. A protocol for data exploration to avoid $1401 \quad$ common statistical problems. Methods Ecol. Evol. 1, 3-14 (2010).

1402 305. Bates, D., Mächler, M., Bolker, B. \& Walker, S. Fitting linear mixed-effects models 1403 using lme4. J. Stat. Softw. 67, 1-48 (2014).

1404 306. Nakagawa, S. \& Schielzeth, H. A general and simple method for obtaining R2 from 1405 generalized linear mixed-effects models. Methods Ecol. Evol. 4, 133-142 (2013).

1406 307. Gelman, A. Scaling regression inputs by dividing by two standard deviations. Stat. Med. $1407 \quad 27,2865-2873(2008)$. 
1409 Fig. 1 | Taxonomic coverage. Number of taxa (in parenthesis), in log scale, per taxonomic class:

1410 from the least (top) to the most (bottom) studied taxonomic class. Only taxonomic classes with 1411 more than 30 observations per factorial model are displayed.

1412 Fig. 2 Sources of variation in species range shifts. Proportion of explained variation either 1413 related to the taxonomic class and position at the range margin (fixed-effect terms in the models) 1414 or to methodological attributes (random effect terms in the models) for each of the 10 factorial 1415 models for which we had data (Supplementary Table 1). Each factorial model represents a 1416 combination of positional parameter (Cen: centroid; Mrg: margins) $\times$ spatial gradient (L: 1417 latitude; E: elevation $) \times$ biological systems $(\mathrm{M}$ : marine; T: terrestrial) $\times$ hemisphere $(\mathrm{N}$ : north; $\mathrm{S}$ :

1418

1419

1420

1421

1422

1423

1424

1425

1426

1427

1428

1429

1430

south). Note that the "Margin" factor variable with two levels (leading edge vs. trailing edge) was only tested in model combinations focusing on margins (Mrg). Error bars represent the distribution of 5,000 bootstrap iterations.

Fig. 3 Mean velocity of species range shifts per taxonomic class. Estimated velocity of range shift per taxonomic class (i.e. effect size) in $\mathrm{km}_{\mathrm{yr}} \mathrm{yr}^{-1}$ and $\mathrm{m}_{\mathrm{yr}} \mathrm{yr}^{-1}$ for (a) latitudinal and (b) elevational range shifts, respectively, after accounting for methodological variation. Outputs are displayed for all possible combinations of positional parameter (TE: trailing edge; CE: centroid vs. LE: leading edge $) \times$ hemisphere $(\mathrm{N}$ : north; $\mathrm{S}$ : south $) \times$ biological systems $(\mathrm{M}:$ marine; $\mathrm{T}$ : terrestrial). Violin plots represent the distribution of 5,000 bootstrap iterations. Stars show significant deviations from zero shift (*: $P<0.05 ; * *: P<0.01 ; * * *: P<0.001)$.

Fig. 4 Degree of coupling between species range shifts and isotherm shifts. Models outputs in terms of (a) proportion of explained variation and (b) effect size related to the velocity of isotherm shifts $(V I S)$, baseline temperatures $\left(B T+B T^{2}\right)$, standardized human footprint index 
1431 (HFI) and two-way interaction terms (VIS:HFI and VIS:BT) for each of the four studied life

1432 forms ( $L F$ : endotherms, ectotherms, phanerogams and cryptogams). Intercept refers to the effect

1433 size of the focal life form. Error bars represent the distribution of 5,000 bootstrap iterations.

1434 Model outputs are displayed separately for marine latitudinal range shifts, terrestrial latitudinal

1435 range shifts and elevational range shifts.

1436 Fig. 5 | Main determinants of the velocity of species range shifts. Results are displayed along

1437 (a) elevational and (b, c, d) latitudinal gradients for both the (a, b) terrestrial and (c, d) marine

1438 realms. Panel a shows the interaction effect between baseline temperatures and the velocity of

1439 isotherm shifts in elevation for ectotherms. Panel b shows the interaction effect between the

1440 standardized human footprint index and the velocity of isotherm shifts in latitude for terrestrial

1441 ectotherms. Panel c shows the interaction effect between baseline temperatures and the velocity

1442 of isotherm shifts in latitude for marine ectotherms while setting the standardized human

1443 footprint index to its median value in the database. Panel $\mathbf{d}$ shows the interaction effect between

1444 the standardized human footprint index and the velocity of isotherm shifts in latitude for marine

1445 ectotherms while setting baseline temperatures to the median value in the database. The two

1446 white lines and the white hatching represent the range of conditions for which marine ectotherms

1447 closely track the shifting isotherms in latitude (i.e. slope parameter not significantly different

1448 from 1 based on 5,000 bootstrap iterations). Note that negative slopes do not necessarily indicate

1449 species range shifts in the opposite direction to isotherm shifts, unless the signs of the two

1450 estimates (for a given combination of baseline temperatures and standardized human footprint

1451 index) are opposite.

1452 Fig. 6 | Maps of the degree of coupling between the velocity of species range shifts and the

1453 velocity of isotherm shifts. Cartograms show the predicted slope coefficient between the

1454 velocity of species range shifts and the velocity of isotherm shifts per $2^{\circ} \times 2^{\circ}$ grid cell along (a) 
1455 elevational and $(\mathbf{b}, \mathbf{c})$ latitudinal gradients for both terrestrial $(\mathbf{b})$ and $(\mathbf{c})$ marine realms. Note that 1456 panel a only displays the predicted slope coefficient for ectotherms. Positive slope values (bluish 1457 colors) close to 1 suggest a perfect isotherm tracking while negative values (reddish colors) 1458 suggest that species are not tracking the shifting isotherms. Note that negative slopes do not 1459 necessarily mean that species are shifting in the opposite direction to isotherm shifts (see Fig. 5). 1460 The number of range shift estimates (i.e. sample size) in each grid cell was used to distort the 1461 map: the bigger the grid cell, the larger the sample size. Grid cells with a black and bold border 1462 display areas where species are closely tracking the shifting isotherms (i.e. slope parameter not 1463 significantly different from 1 based on 5,000 bootstrap iterations). 
Bivalvia

Chondrichthyes

Polychaeta

Lecanoromycetes

Phaeophyceae

Reptilia

Mammalia

Florideophyceae

Malacostraca

Pinopsida

Gastropoda

Polypodiopsida

Amphibia

Arachnida

Bryopsida

Actinopterygii

Liliopsida

Aves

Insecta

Magnoliopsida
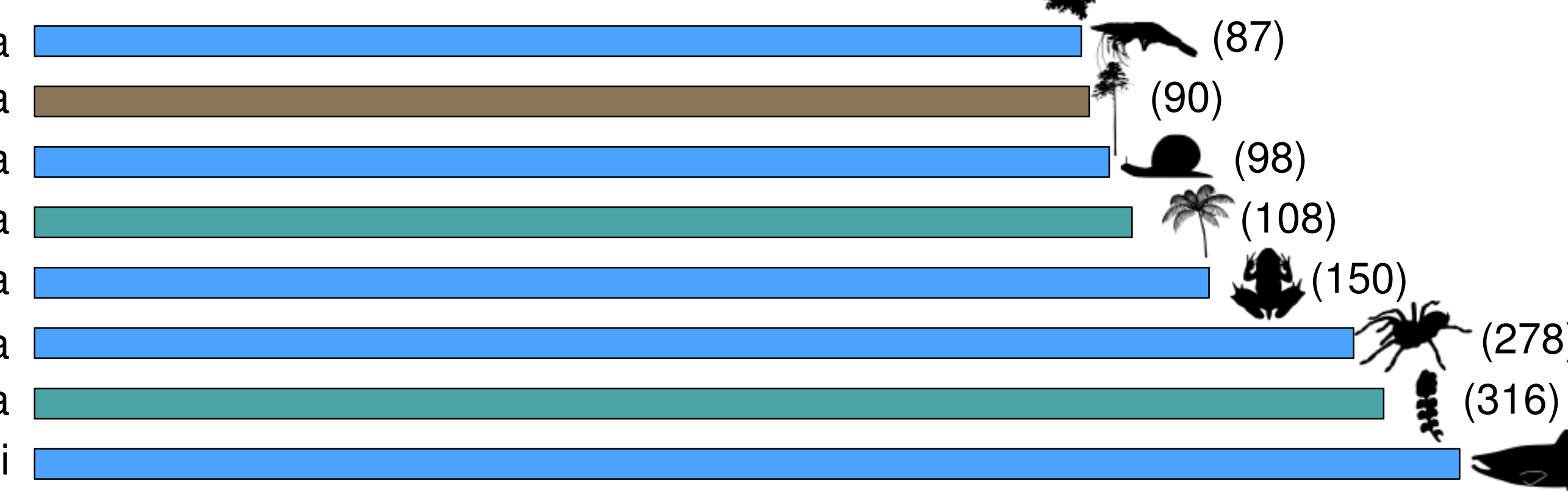

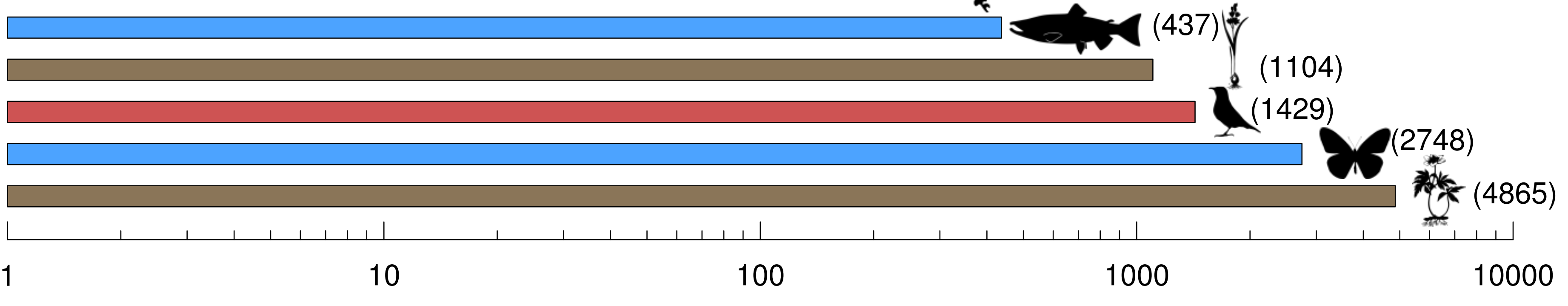

Number of taxa 


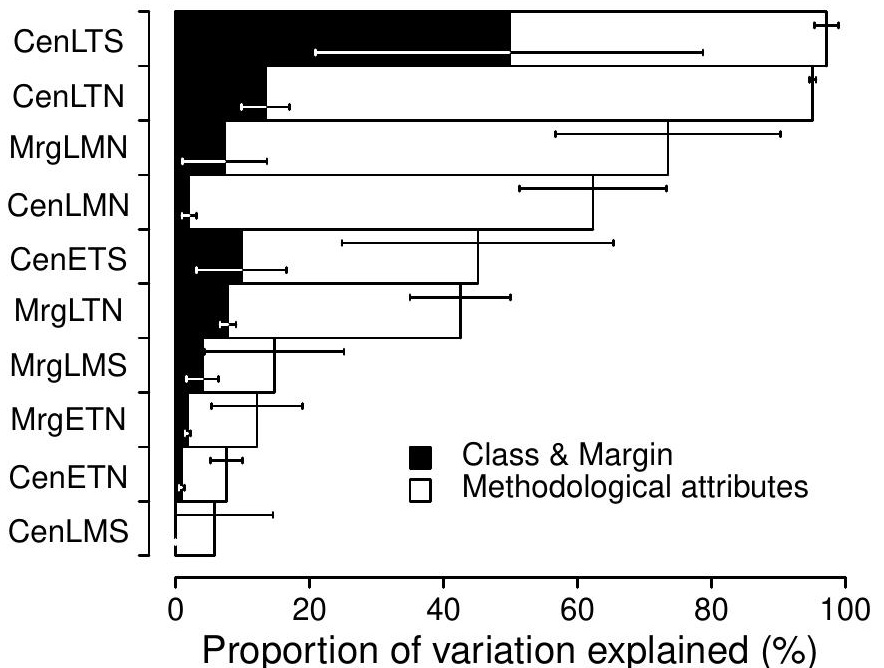


Reptilia $\longleftarrow *$ Aves Bryopsida

Polypodiopsida Aves

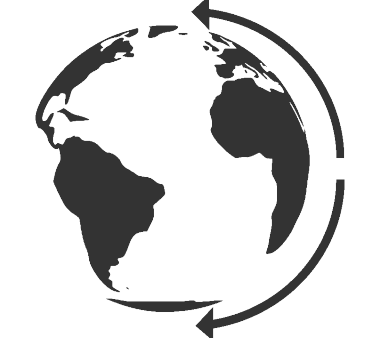

\section{Ecosystem}

Position

Hemisphere

\begin{tabular}{|c|c|c|c|c|}
\hline & $\mathrm{M}$ & LE & C & $\mathrm{TE}$ \\
\hline & 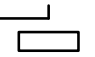 & 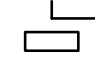 & $\frac{1}{\square}$ & $E$ \\
\hline & $\square$ & $\square$ & D & $\sqsubset$ \\
\hline & $\square$ & 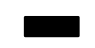 & $\square$ & 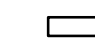 \\
\hline & $\square$ & $\square$ & $\square$ & - \\
\hline & $\square$ & $\square$ & $\omega$ & $\sqsubset$ \\
\hline & $\square$ & $\square$ & $\omega$ & $\sqsubset$ \\
\hline & c & 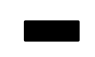 & $\square$ & $\sqsubset$ \\
\hline ᄃ & 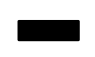 & $\square$ & $\square$ & - \\
\hline & $\square$ & $\square$ & $\omega$ & $\sqsubset$ \\
\hline 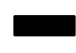 & $\square$ & $\square$ & $\omega$ & $\sqsubset$ \\
\hline & $\square$ & $\square$ & $\square$ & - \\
\hline 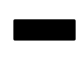 & $\square$ & 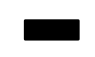 & $\square$ & $\bar{E}$ \\
\hline & $\square$ & $\square$ & $\square$ & - \\
\hline 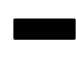 & $\square$ & $\square$ & w & $\sqsubset$ \\
\hline & $\square$ & $\boldsymbol{n}$ & $\square$ & $\sqsubset$ \\
\hline 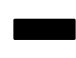 & $\square$ & $\square$ & $\square$ & - \\
\hline$\square$ & $\boldsymbol{D}$ & $=$ & $\square$ & $\square$ \\
\hline $\boldsymbol{\theta}$ & $\square$ & $\boldsymbol{D}$ & $\square$ & $\sqsubset$ \\
\hline$\square$ & $\boldsymbol{D}$ & $\square$ & $\square$ & 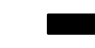 \\
\hline 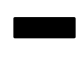 & $\square$ & $\boldsymbol{\omega}$ & $\square$ & $E$ \\
\hline 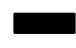 & $\square$ & $\boldsymbol{\omega}$ & $\square$ & $\sqsubset$ \\
\hline- & $\square$ & $\boldsymbol{\theta}$ & $\square$ & $\sqsubset$ \\
\hline$\square$ & $\boldsymbol{E}$ & 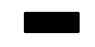 & $\square$ & $\sqsubset$ \\
\hline$\square$ & 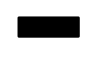 & $\square$ & $\square$ & 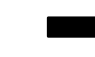 \\
\hline- & $\square$ & 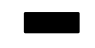 & $\square$ & $\sqsubset$ \\
\hline$\square$ & $\boldsymbol{\theta}$ & $\boldsymbol{\theta}$ & $\square$ & $\sqsubset$ \\
\hline$\square$ & 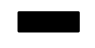 & $\square$ & $\square$ & 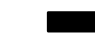 \\
\hline$\sqsubset$ & $\boldsymbol{\theta}$ & $\square$ & m & $\bar{E}$ \\
\hline$\square$ & c & $\square$ & $\omega$ & $\sqsubset$ \\
\hline- & $\square$ & $\boldsymbol{\sigma}$ & $\square$ & $\square$ \\
\hline E & $\square$ & $\square$ & 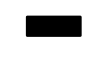 & $\sqsubset$ \\
\hline$\square$ & & $\square$ & $\boldsymbol{m}$ & - \\
\hline$\square$ & = & $\square$ & 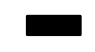 & $\sqsubset$ \\
\hline$\square$ & E & $\square$ & $\square$ & \\
\hline$\square$ & 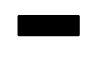 & $\square$ & $m$ & $=$ \\
\hline 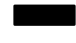 & $\square$ & $\square$ & $\square$ & 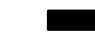 \\
\hline$\square$ & = & $\square$ & $\square$ & - \\
\hline$\square$ & 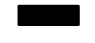 & $\square$ & $\boldsymbol{\sigma}$ & $\square$ \\
\hline$\square$ & - & $\square$ & $\boldsymbol{\theta}$ & $\sqsubset$ \\
\hline$\square$ & & $\square$ & $\square$ & \\
\hline$\square$ & 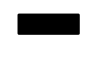 & $=$ & $\square$ & $\sqsubset$ \\
\hline$\square$ & $=$ & $E$ & $\square$ & $\sqsubset$ \\
\hline$\square$ & - & $\boldsymbol{\sigma}$ & $\square$ & $\sqsubset$ \\
\hline$\square$ & - & $\boldsymbol{\theta}$ & $\square$ & $\leftarrow$ \\
\hline$\square$ & 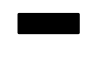 & $\square$ & $\square$ & E \\
\hline$\square$ & & - & $\square$ & $\leftarrow$ \\
\hline$\square$ & - & $\square$ & $\square$ & \\
\hline & & $\square$ & 0 & \\
\hline
\end{tabular}

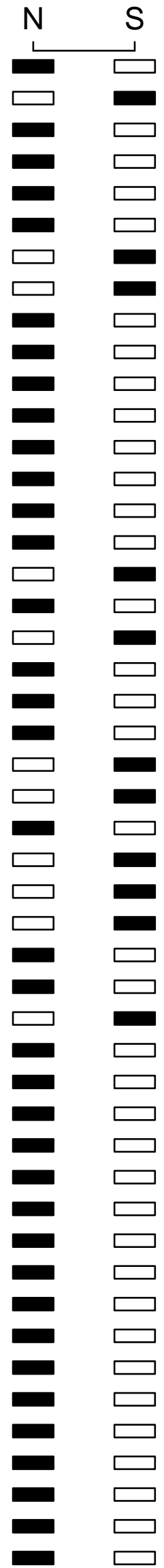

Velocity of range shift ( $\mathrm{km} /$ year)

b

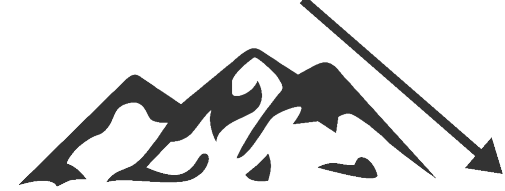

Actinopterygii

Magnoliopsida

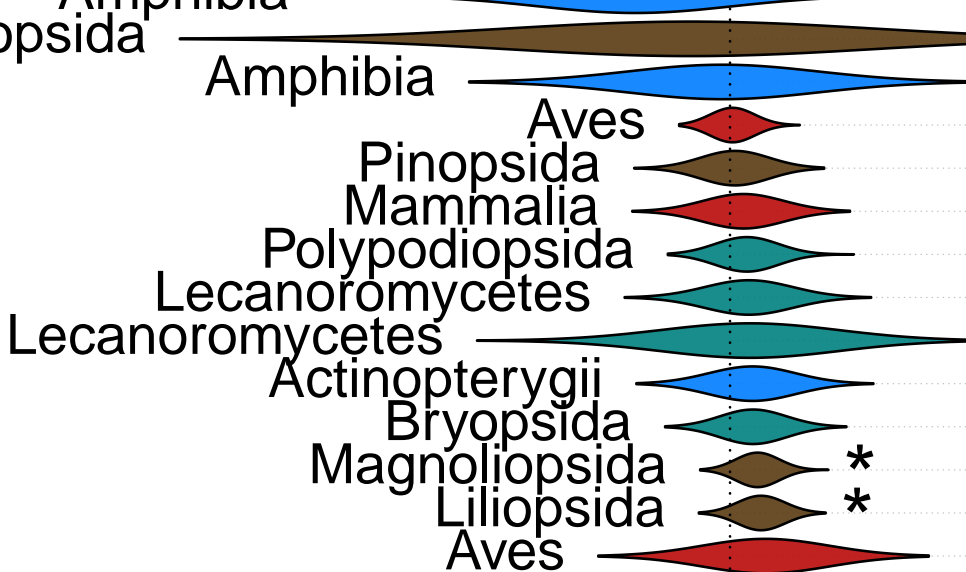

Polypodiopsida

$\longrightarrow$

Insecta $\sim^{* \star}$

Liliopsida

Mammalia $=$

Pinopsida

Aves $\overline{\pi_{* *}}$

Magnoliopsida Aves $\approx \star \star *$

Actinopterygii

Magnoliopsida $\overline{\text { Aves } \sim \star * *}$

Polypodianmalia

Polypodiopsida

Insecta

Amphibia $\frac{\text { Magnoliopsida }}{\Delta \star \star}$

Amphibia $\frac{\text { Magnoliopsida } \sim \star \star \star}{\text { Amphibia }}$

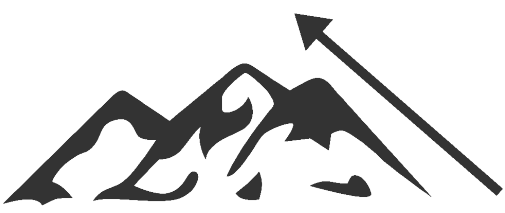

Ecosystem Position Hemisphere

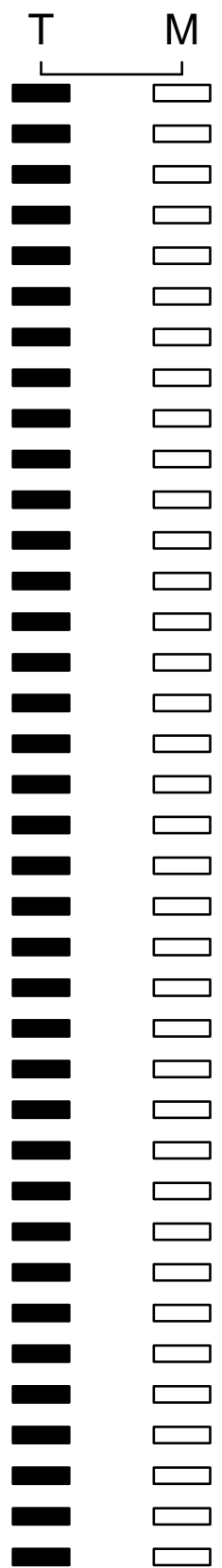

Velocity of range shift (m/year)
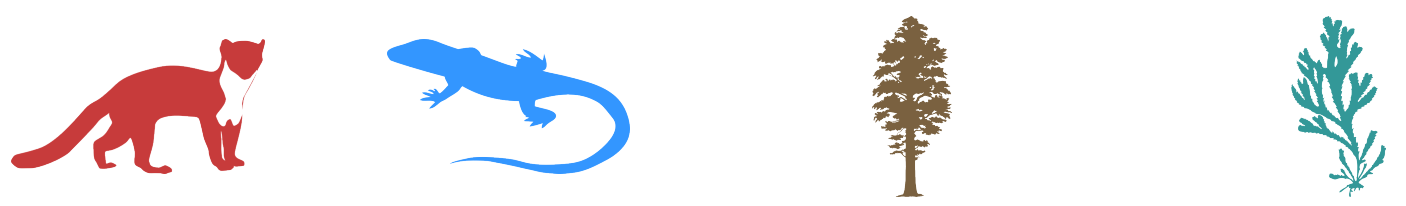

Endotherms Ectotherms Phanerogams Cryptogams 
Terrestrial latitudinal Marine latitudinal

Elevational

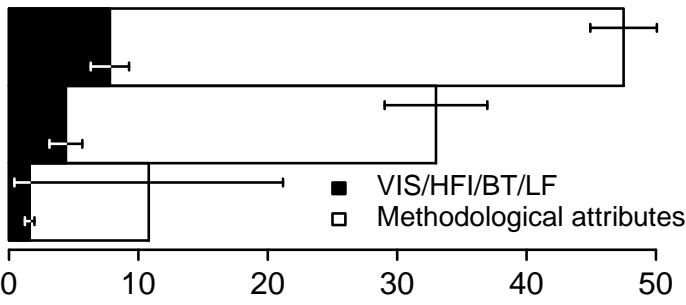

Proportion of variation explained (\%)

b
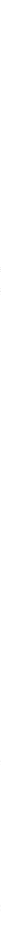

\section{Range shifts}

- Marine latitudinal

Terrestrial latitudinal

Elevational 

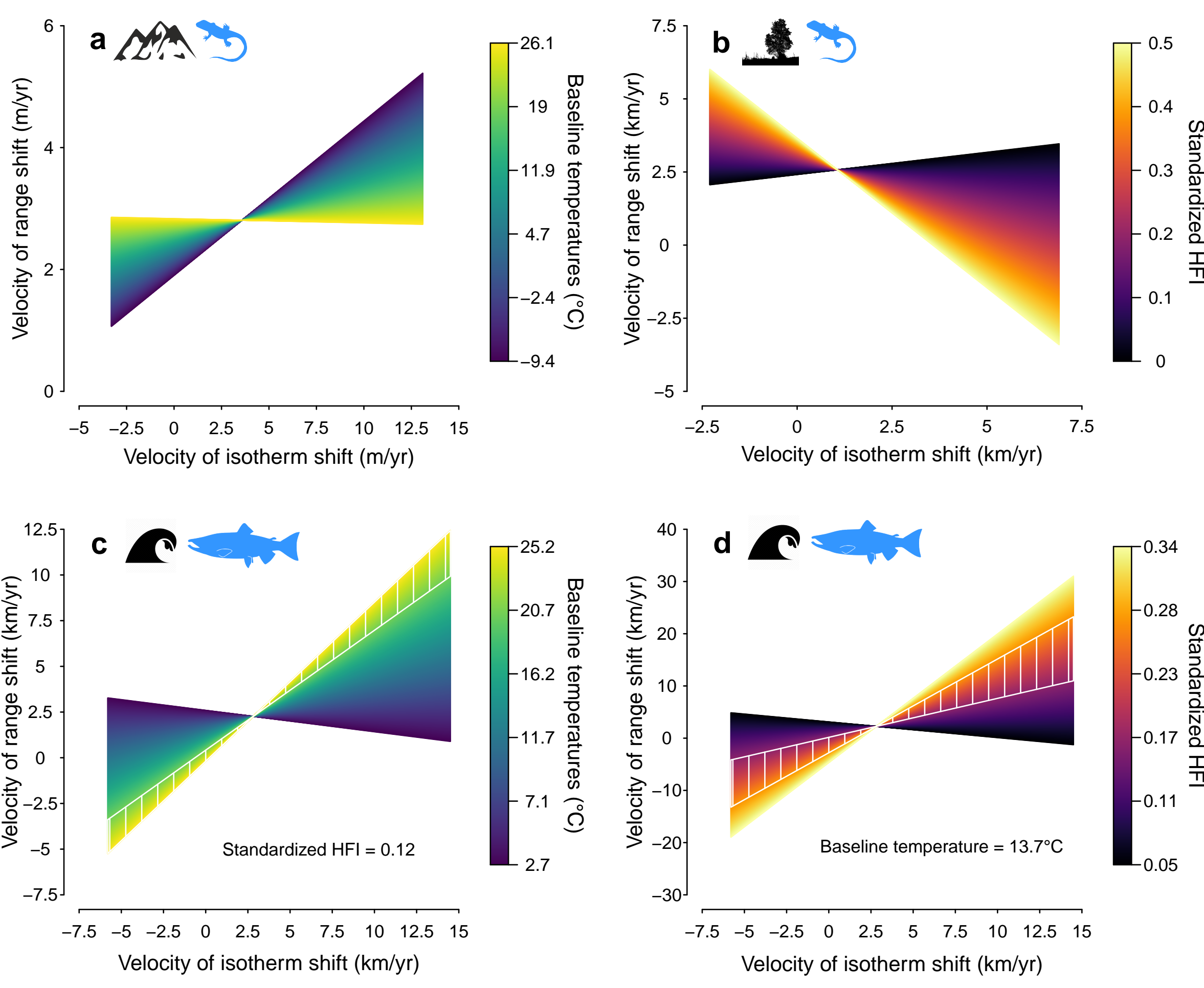
a

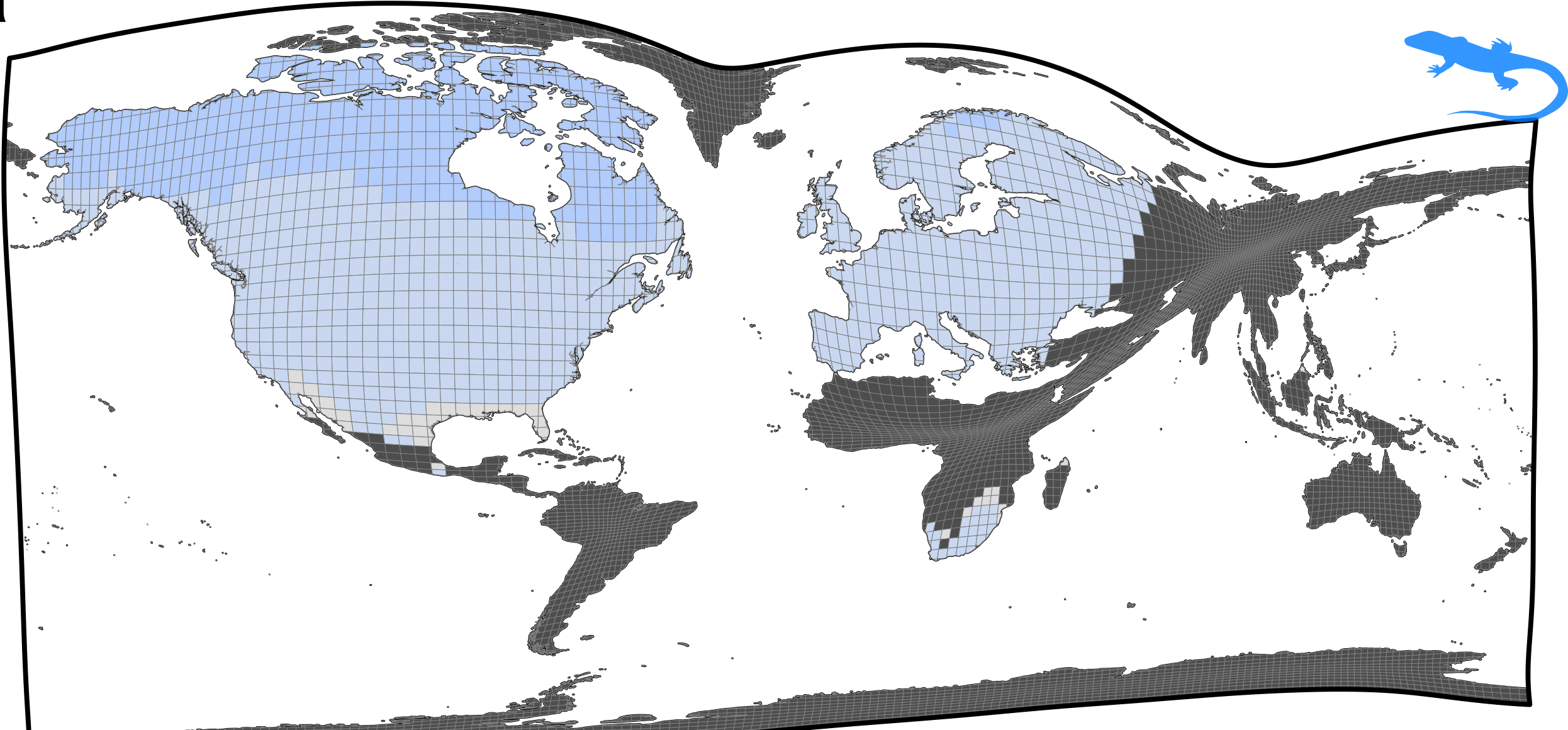

b

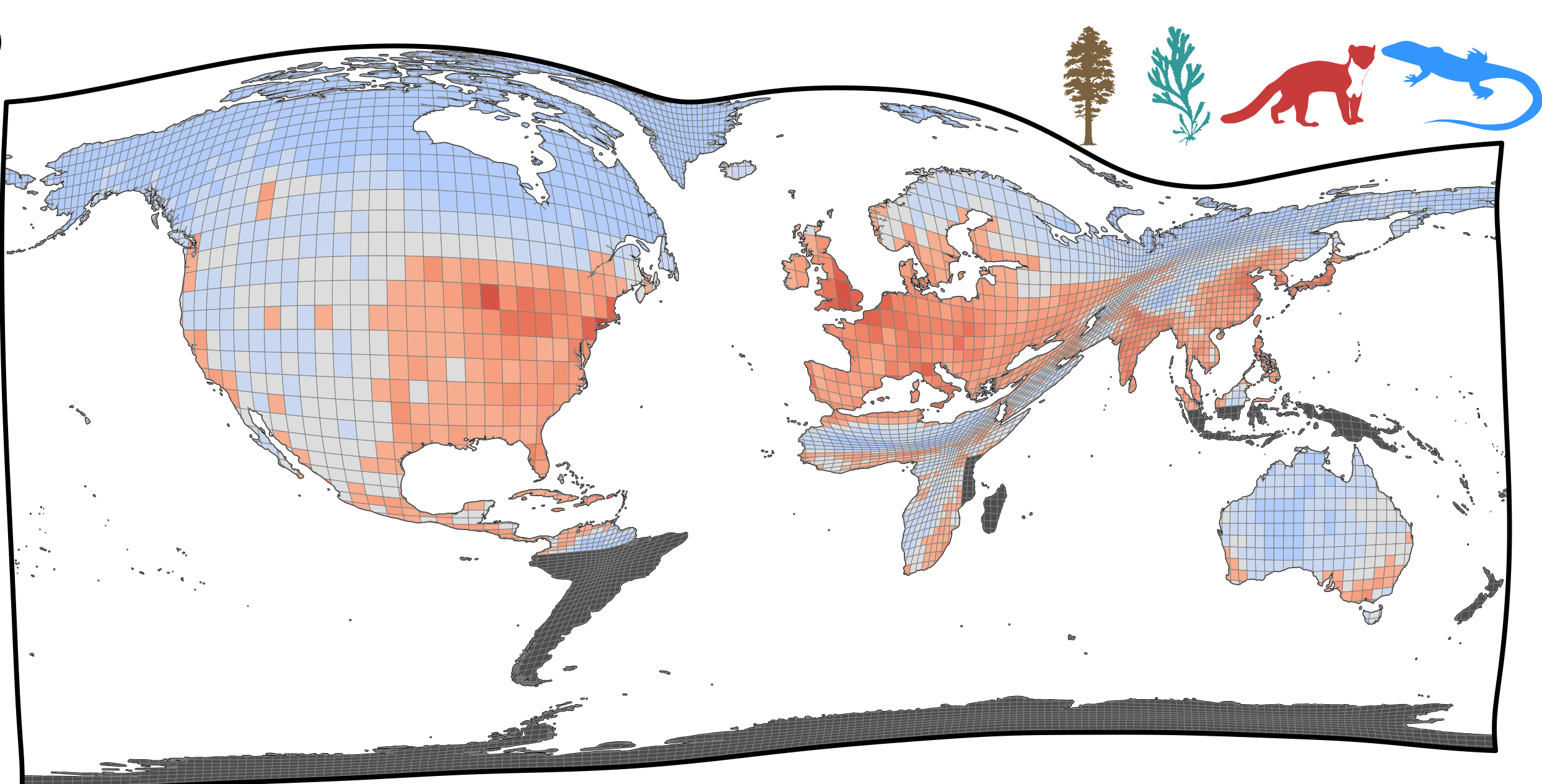

C

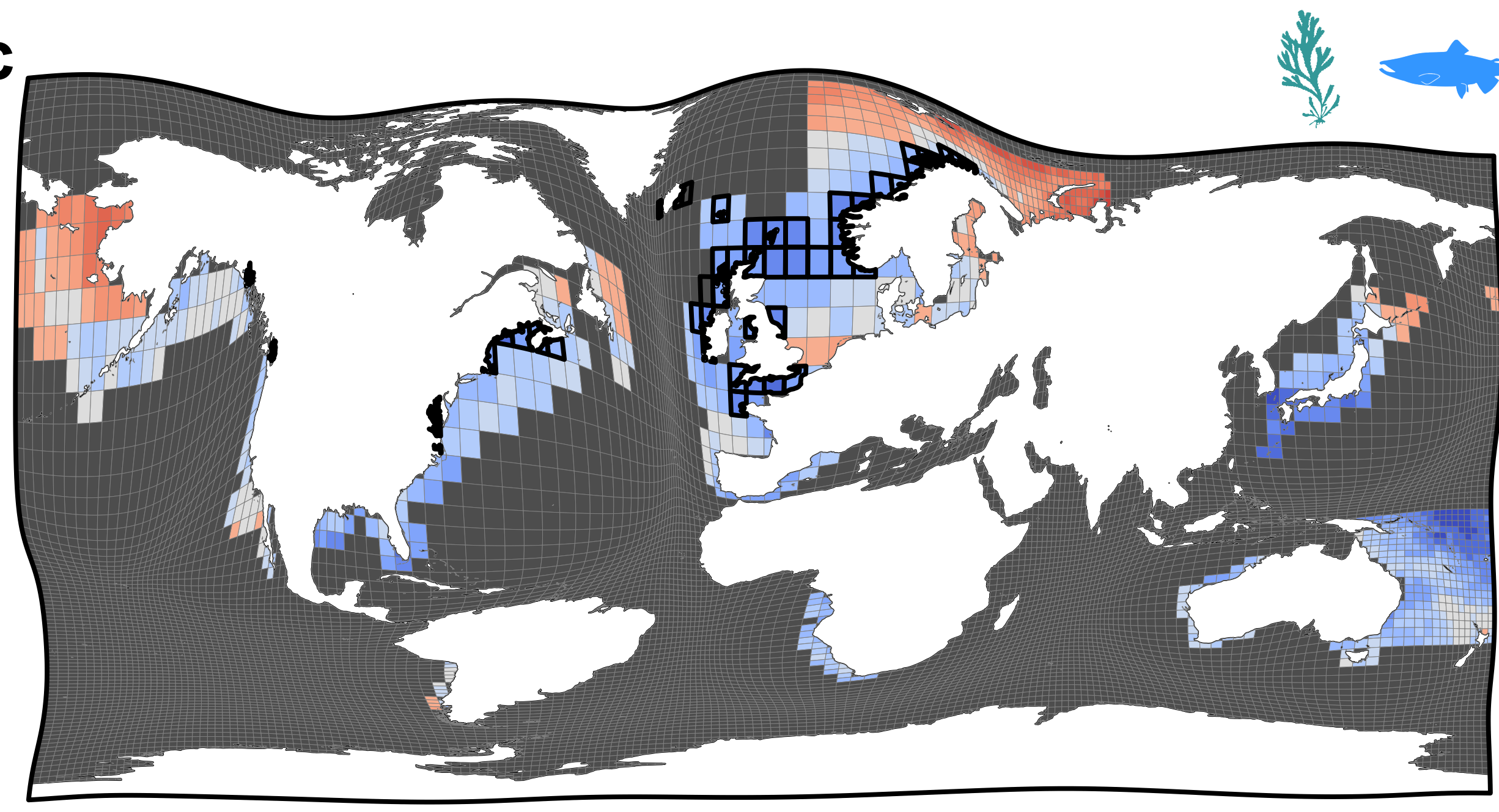

